Euskal ikerketen aldizkaria | Revue d'études basques |

Revista de estudios vascos | Basque studies review

$20 \mid 2017$

Numéro $X X$

\title{
Bi eta bere askazia
}

\author{
Joseba A. Lakarra
}

\section{OpenEdition}

Journals

Édition électronique

URL : https://journals.openedition.org/lapurdum/3464

DOI : 10.4000/lapurdum.3464

ISSN : 1965-0655

Éditeur

IKER

Édition imprimée

Date de publication : 1 janvier 2017

Pagination : 17-43

ISBN : 978-2-95534-135-3

ISSN : $1273-3830$

\section{Référence électronique}

Joseba A. Lakarra, «Bi eta bere askazia», Lapurdum [Linean], 20 | 2017, Sarean emana----an 01 janvier 2021, kontsultatu 03 septembre 2021. URL: http://journals.openedition.org/lapurdum/3464 ; DOI: https://doi.org/10.4000/lapurdum.3464

Creative Commons - Attribution - Pas d'Utilisation Commerciale - Pas de Modification 4.0 International - CC BY-NC-ND 4.0 


\section{Bi eta bere askazia'}

Joseba A. LAKARRA

UPV/EHU - Euskaltzaindia (EHHE)

Bergara, zeñatu ta aigara (errefrau zaharra)

Etymology is from beginning to end a matter of balancing probabilities, and thick-set with uncertainties and chances of error... All such erro rs, it is hoped, will be viewed with a reasonable degree of indulgence, considering the novelty and the extreme laboriousness of the undertaking (William Dwight Whitney 1885: xi f., apud Vennemann 2003: vii).

\section{Sarrera}

Xarles Bidegaini ez da esan beharrik lexikografia, semantika eta etimologia ${ }^{2}$ lan nekoso eta irristakorrak direla, arazoz beteak, usu lilluren eta areen gainean eraikiak, beti ere gutxieneko tinkotasun enpiriko eta kontzeptualen bila. Omenduak badu eskarmentu ederrik alor malkartsuotan barrena eta nago etorkizunean ere Xarlesek emango digula horietan eta bestetan bere trebeziaren erakusgarri gogoangarririk. Hala biz! Artean, har bitza gogorik hoberenez eskaini adabakiok; partez bederen, aurreko maisuengandik bilduak izaki, ez ahal zaizkio guztiz okaztagarri egingo.

(1) “(...) en matière de sens, on n'a pour guide qu'une certaine vraisemblance, fondée sur le "bon sens ", sur l'appréciation personnelle du linguiste, sur les parallèles qu'il peut citer. Le problème est toujors, à tous les niveaux de l'analyse, à l'interieur d'une même langue ou aux différentes étapes d'une reconstruction comparative, de déterminer si e[t] comment deux morphèmes formellement identiques ou comparables peuvent être identifiés par leur sens. Le

1. "Espainiako Ministeritzako "Monumenta Linguae Vasconum" (V) [FFI2016-76032-P] eta: Textos Arcaicos Vascos y Euskera Antiguo" (FFI2012-37696) egitasmoaren, Eusko Jaurlaritzako "Historia de la Lengua Vasca y Lingüística Histórico-Comparada" GIC.IT698-13 Ikerketa Talde Iraunkorraren eta UPV/EHUko UFI 11/14aren egitekoen barnean kokatzen da lan hau.

Eskerrak eman nahi dizkiet Borja Ariztimuño, Ricardo Gómez, Ana Iriarte, Julen Manterola, Iñaki Segurola eta Blanca Urgell lankide eta adiskideei hemengo hainbat gai eroapen eta kiroltasun handiz entzuteagatik eta baita hainbat ohar eta zuzenketa interesgarri egiteagatik (orotan ez jarraitu arren); baita nire luzamendua jasan duten argitaratzaileei ere. Gelditzen diren huts eta akats guztiak neureak dira.

2. Beren buruak à la page ikusten dituzten zenbaitek ez bezala, arestian joan zitzaigun Calvert Watkinsek hizkuntzalaritza historikoaren oinarritzat zuen etimologia, cf. Watkins 1990. Gogoratzekoa da Koldo Mitxelenak Robert King-en liburuari egin iruzkinean (Mitxelena 1971) ezarri bereizkuntza benetako diakronisten (berreraiketan arituen) eta "dena liburuetan" ikasi zutenen artean, azken hauek inork egindakoa arropa berriz janzteko gai izan arren. 
seul principe dont nous ferons usage dans les considérations qui suivent, en le prenant pour accordé, est que le "sens " d'une forme linguistique se définit par la totalité de ses emplois, par leur distribution et par les types de liaisons qui en résultent. En présence de morphèmes identiques pourvus de sens différents, on doit se demander s'il existe un emploi où ces deux sens recouvrent leur unité. La réponse n'est jamais donnée d'avance" (Benveniste 1954: 289290; letra etzanak nireak dira [J.A.L.]).

Benvenistek ere bazekien zer ari zen etimologi-jardunean arazotsuena alderdi semantikoa dela zioenean; ez da baieztapen istilutsua: horretan dihardugunean ez dugu lege fonetikoen erregulartasunaren pareko edo antzeko oinarri ez lanabesik eta zail da esanahi eta adieren bilakabidean erregularitate esanguratsurik erdiestea. Egiteko honetan gramatikalizazioaren ikerketak bere izaera holistikoagatik etimologiagintzan eta semantika diakronikoan ere laguntza berebizikoa eman lezake eta horren hainbat adibide eman izan da dagoeneko, euskarazko zenbait tartean; ikus Lakarra 2013b eta 2015b.

Halere, gramatikalizazioaren hurbilketa hau azken hamarkadetan garatu baino lehen ere, etimologiagintzan bazen bide zenbait izan litezkeen hurbilketa kontaezinak mugatzeko, filologoaren intuizio hutsaz landa etimologia konparatua, esaterako. Ohartzen bagara, adibidez, pesc-ado partizipioa dela erromantzez, Mitxelenaren *arrani-tik atzerago jotzeko aukera seguruena (bestela ere akats nabarmenik ez du nire ustez) *arran-i —eta arrano < *arran-no (<...); cf. Lakarra 2011b- zatitzea dugu. ${ }^{3}$ Halaber, hortz < hor + -tz analizatzeko bel-tz, bor-tz... (baina ez **ga-tz) eta erromantzezko canino < can + -ino dugu lagun, ustez aski litzaigukeen CVC forma kanonikoaz landa, cf. Lakarra 1995hh. Orobat, Lakarra 2002n bardal bart *gaur-da-tik atera nuen arrazoi formal hutsengatik; ${ }^{4}$ alabaina, cf. Watkins 1965, paraleloak badira, indoeuroparrak (latinetik hasita) eta hizkuntza amerindiarretakoak (menominikoak eta ojigwakoak). 2002ko etimologia hori are seguruago bilakatzen da hizkuntza amerindiar horietan egitura bera aurkitzen baita uda da eta negua da-rentzat ere. Negu ekialdeko erromantzetiko mailegua dugu euskaraz (honetan Schuchardtek asmatu zuen), baina uda-ri dagokionez, Mikoletaren euda lagun, *egu-da-ra iritsi ahal gara (B. Ariztimuñoren iradokizuna); gainera, J. Manterolak diostanez BN-n ortzi da gordetzen da "ekaitza dator" esateko. Konparazioagatik izan ez balitz barda eta uda-ren arteko egitura kidetasuna oharkabean mantenduko bide zen, orain arte legez, garrantzirik gabeko hoskidetasun txiki bat legez.

Charles de Lamberteriek (2000: 127-131) badu Lakarra 2002an proposatu —artean harena ez nuen ezagutzen - ipurdi-ren etimologiaren (*ibi-erdi, ipirdi zaharraren bitartez) grekerazko eta armenierazko erabateko paraleloa (pro:ktos): "On met ainsi en évidence une motivation: l'orifice anal doit sa désignation au fait qu'il est l'endroit par où les matières fécales

3. Orain -cf. Lakarra prest.-1, lehenago 2011a, etab.- bietako arran- hori ere zatika genezake, baita formalki erkagarri diren arrats, arbin eta ardan- ere, besteren artean. Bidenabar, Benvenistek Les institutions zoragarrian IE ezkontzaz zekarrenean inspiraturik berreraiki nituen errain eta arreba-ren etimologiak.

4. Gaur $<$ gau + haur ezaguna zen lehenagotik, jakina. Bidenabar, merezi du kasu egitea $-r>-R$ bilakabideari, dardarkari bortitzaren hedadura hitzen handitzearekin lotua baita, nahiz kokagune horretan, nahiz barnekoan, cf. Lakarra 201 la eta prest.-1. 
achèvent leur parcours, l'extrémité d'une "voie de passage". 5

Izan ere, motibazioaren bilaketa dugu betidanik etimologiaren (eta, beraz, berreraiketaren) oinarrizko laguntza:

(2) "Nous touchons ici à la notion de motivation, reconnue comme centrale en linguistique depuis Saussure, et où se manifeste la tensión entre synchronie et diachronie. C'est un fait bien connu qu'un terme motivé dans une synchronie donnée peut devenir opaque dans un état ultérieur de la langue, car l'évolution disloque les familles de mots" (de Lamberterie 2000: 119).

"Depuis les debuts de la grammaire comparée, les indo-européanistes n'ont cessé d'exercer leur sagacité pour trouver aux numéraux une étymologie au sens que nous donnons ici à ce mot, c'est-à-dire pour restituer la motivation qui preside aux désignations" diosku de Lamberteriek (2000: 120) eta ondokoa ematen adibide ugarien artean:

(3) "Voici un autre exemple de motivation. Selon une analyse d'Alfred Heubek largement acceptée aujourd'hui, le numéral hittite mieyawas "quatre" remonte à un adjectif i.-e. *méy-u "amoindri, diminué"... [grekozko eta latinezko "laburtu" aditza eta konparatiboa "laburrago" tartean] ... cette dénomination fait référence à la main considérée sans le pouce" (de Lamberterie 2000: 122 [azken etzanak neureak dira, JAL]).

Guztia begitantzen zait interesgarri, euskarazko laur eta labur-en arteko kidetasuna (cf. Lakarra 2010) beharbada lillura hutstzat ez jotzeko arrazoi aski izan dezakegula, hasteko. Baina hor etzanean eman dudana gehienik, hori baita zenbaketa-sistema zaharren oinarri, aipatu nire lan horretan amazoniar sistemen azterketatik Epps 2006ren bitartez bildu eta euskara zaharrarentzat aldarrikatu nuena. Halaber, eskuaren atzeko partean ere, behatz lodia kontaketatik kanpo uzten zen, horrela lau "mendixka" ikusiaz eskugain bakoitzean, zortzi (< zorrotzi, IE eta beste hainbat hizkuntzatan legez); ikus Lakarra 2010.

Iruditzen zait dagoeneko motibazioaren azterketak eskeini digula hurbilketa formalagoekin batera etimologia-ikerketak aberasteko bere interesaren erakusgarririk eta gure artean ere zilegi ez ezik beharrezko dela hori garatzea de Lamberteriek aipatu indoeuropar hizkuntzalari hoberenen aspaldiko ohiturari lotuaz. Horrenbestez, honako lan honetan hibairen etimologia-proposamen baten zuzenketatik abiatuaz, bi 'goi's eta honen eratorri den bide-

5. Lehenago (de Lamberterie 2000: 128) * pro:k erroaz 'traverser, aller jusqu'au bout, accomplir un parcours jusqu'à son terme' (Chantraine) eta 'traverser, franchir, passer' adierazi nahi duela diosku, hots, gure *bi horren [kasu honetan *ibi-ren] adiera bertsua; kasu $\$ 3$ hemen etzanez jarri esanahiaz.

6. "Nire ustez goi bera go da jatorrian; gohen zaharragoak erakusten duen bezala, goihen berriagoaren aldean. Nire hipotesian, goi horretako -i hasperenaren aurretik sortua litzateke lehenik goihen eta halakoetan (zure saihets eta halakoen eredura), eta gero lexikalizatuko zen goi", diost J. Manterolak eta bat nator dioen guztian. Alabaina, -bi (gogora, besteak beste, goi-k hartzen ez dituen oi $>w i, g w>b$ eta $-C>\emptyset$ gramatikalizaziokoa) data askoz zaharragoetan garatuko zen. Goiztiarrago (eta gramatikalizatuago) zelako, hain zuzen, ez zen **mi- sortu; cf., aldiz, mihi< *bini. 
rekin lotu hainbat hitzez arituko gara, hitz-familia bere osotasunean aztertzeak berreraiketarako ekarri ohi dituen emendioak profitatuz ${ }^{7}$ eta, bereziki, hitz eta familia horiek nondik eta nola iritsi diren beren egoera historikora ikertzen aitzinatu nahiz.

\section{Hibai-ren etimologia berria}

Aurreko lanetan (cf. Lakarra 2015a: \$3.1.3) hibai-ren etimologiaz egin izan dudan proposamena zertxobait aldatzeak abantaila handia eman bide liezaguke hitz horren formari, semantikari nahiz hitz-familiaren hedadura eta sendotasunari dagokienez. Hots, *hur-ban-iren ordez —cf. 'cortada', etc. eta luban, lugan, lubaki... < *lur-ban— *hur-bar-bi-tik abiatuaz, aurrekoarekin lortu teoria-garapen eta datu-azalpenak oro gordetzeaz gain, beste zenbait hobari ere erdietsiko genuke. Izan ere, dagoeneko Mitxelenak bestelako bide bat irekia zuen, egokiagoa orain dakusadanez:

(4) "Sin salir del vascuence, es difícil que se puedan ver en ibar e ibai derivados, por medio de dos sufijos distintos (-ar bien documentado, pero -ai sin apoyo), de un mismo radical que, si se le suprime todavía el "prefijo" i-, quedaría reducido a la sola consonante b, lo que es por lo menos sorprendente. Al contrario, sería natural pensar que ibai es un deribado de ibar, cuya consonante final se habrá perdido como es normal en compuestos y derivados antiguos [oharra belar-en eratorri eta konposatuez]. No es posible, sin embargo determinar qué forma precisa tenía el sufijo que hoy aparece reducido a -i" (Mitxelena 1958: 102). ${ }^{8}$

Alegia, funtsean, hibai-ren h- eskubitik letorke hidoi-ren kasuan legez (cf. Lakarra 2009/2013), eta ibar edo idor-en ez bezala, nahiz hauek ere hur-etik atereak diren. Horrenbestez, lehen bezalatsu iraungo lukete lanotan (ikus Lakarra 2008a eta 2015a: §3.1.2) hur-en eratorrikonposatuen arteko ezberdintasunetarik erdietsi ondorioek, baina proposamen berriarekin —abantailen zerrendarekin hasteko-, ez genuke sudurkaritasun aztarnarik utzi ez duen *-nbaten beharrik, besteak beste (ikus 5. oh., amaian). Haatik, ${ }^{*}-r>{ }^{*}-h$ premiazko genuke, baina horren paraleloak badira ugari enparatuko hainbat errotan, hur- > uh-, hor- > oh, etab.; ikus Lakarra 2015a.

Hibai-ri buruz esandakoak bizkai-rentzat ere balio bide du, azken bi osagaiei dagokienez, bederen: *bi-z-bar-bi. ${ }^{9}$ Bizkahi bat baino gehiago da -h-rekin Donemiliagako Becerro-an Peterson 2013n ikus litekeenez; bidenabar, bilakabide hauetan (*-bar- > *-bah-)

7. Ikus Sagart 1997 txinerazkoez eta Schuh 2011 hausaz eta kutxitikoaz; Lakarra 201la eta gainerakoetako batzutan badira oharrak euskarazko hitz-familia zenbaitez.

8. Ahapaldi honen aurretik eta ondotik bizkai (cf. Bizkai-a, Iruñe-a: Gipuzkoa, Araba) eta bizkar-en forma, esanahi eta hedadurari buruzko ohar interesgarriak dira. Orpustanek (2000: 150) "bizkar et bizkai 'croupe, élevation' dakar, zuzen noski; ez hainbeste "bai ancêtre du moderne ibai" dioenean (171). Hor-hemen nire lanari zuzenean lotutako zenbait puntu aipatu ditut; Orpustan 1999-ri buruz Salaberriren iruzkinari (1999) nagokio.

9. Cf. $\$ 11$ hasiera *biz- haboroz (bizkar barne); hor aipatzen da, orobat, ibi : hibai :: zubi : zumar $\therefore \ldots \mathrm{x}$ : bizkai proportzioaren bigarren zatian -bar- (eta *b- > $\varnothing$ - [ikus 43 eta 48. oh.]) kenduta beharbada genukeen izpi. 
badugu beste $* r$ - $>$ *h- bat ere Lakarra 2015a-koei gehitzeko modukoa.

Hibai-ren esanahira joaz, arazo gutxi dakusku; iturriek dioskutenez, B, G, L eta BN-ko testuetan 'uhaitz, erreka' esanahiarekin erabiltzen bada ere nagusiki — GN eremuan ugalde dugu gehienbat balio horrekin-, pentsa liteke hitza antzina 'ibi'-tik hurbil zela: cf. en el bado de Ybayçaual (Bizkaia, 1475); Pouv: "ur ibaia, gué, rivière guéable"; Moret: "que algunas regiones de los vascongados ibai llaman al río, aunque en Navarra suena el vado", etab.

Aldai-ri buruz (Mitxelena 1973: 302 zb.) -i atzizkia eta alde oinarria (33 zb.) markatzen dira, baina atzizki horren balioaz ezer esan gabe; *alde-Ci (*alde-bi, zehatzago) batetik ere emaitza bera genuke, -C->- $\varnothing$ - bilakatu ondoren, hibai, bizkai eta gainerakoetan legez.

Garai. Inoiz adierazi izan dut ez nintzela seguru garai < gara + -i banatu behar ote zen —nahiz Mitxelenari (1973: s.u.) aski zaion "es derivado de gara"-, lehen zatia zer den ez jakiteaz landa, ${ }^{10}$ gainera, clauis-etik abiatuz *kalabe $>{ }^{*}$ gara(b)e > garai bitartez arazo larririk gabe baikenuke. Alabaina, paralelismo hertsia da *hur-(bar)-bi (> ibi, hibai) eta *gar-(bar)-bi (> garbi, garai)-ren artean [*gar-i buruz ikus §4 akaburantz] eta hara, Ezkaraiz mintzo, J. Manterolak dakarkidan pasartea: "una casa que uocitant Sancta Maria de Hubaho, que est sita super villam que uocatur Yzcarahi iuxta montem" (FDMPV 27, 1110 urtekoa). Bizkahi-rekiko antzekotasuna bistakoa da.

Are gehiago, hiruko egitura bertsua genuke zumai-n ere (*zur-bar-bi, cf. zubi< * zur-bi). Mitxelenak zumai-rekikoak honela biltzen ditu Apellidos Vascos-en (1973: 623. zb): "zuhai(n), zugai, zumai "forraje, heno" (de *zunai): Zugadi, Zumaya, Mocoçuhain". OEH-n ere (nire ustez oker) zumai "zuhain-2"-n biltzen da, baina jatorrizko *-bi-rekiko lekukotasun aski argi batekin hornitua, oraingoan: "Forraje en toda su extensión, zugaia; si es de sólo grano, zaldalea" A(ra)q(uistain) 1236. "Fourrage" VocBN. "La partie supérieure des tiges de mais ou des feuilles desséchées, et qu'on donne à manger aux bêtes bovines" (Etzanak neureak [JAL]).

Sabai-ri ere oso ongi letorkioke hibai eta bizkai-ren -bai horri egokitu azalpena, bai esanahiz (inon baino garbiago litzateke -bi 'goi'-ren arrastoa) eta baita formaz ere. Alabaina, haietan ez bezala tarteko urrats egokia (*sa-bar) falta dugu.

Zelai-ri dagokionez, gauzak zailago dira baina ez zait ahaztekoa iruditzen zelar-ekin (eta Haritz-zelhar-ekin) egin bikotea, bizkar bizkai : ibar hibai eta zumar zumai bezalabezalakoa. Egia da Jaureguiçelaheta (ArchSegI 1449) eta Jaureguiçelaeta (1448) bana direla Manterolaren tesiko bilduman baina 11 aldiz Jaureguiçelayeta (behin Juar-) eta beste behin -çilayeta eta, beraz, Ibaieta > Ibaeta legez, zelai-tik ${ }^{11}$ (<* zel-bar-bi) azal ditzakegula deritzot.

Ikusi dugunaren arabera, hibai eta ibi (besteak beste) oso gertu ditugu esanahiz ez ezik osagaietan ere: *hur-bar-bi / *hur-bi. Hauei gehitu ahal zaizkien beste hiruzpalau bikote ere

10. Cf. Apellidos, s.u. gar "En cuanto a gara 'elevación, altura, etc.' sigue siendo para mí un enigma lexicográfico: lo único de cuya realidad no se puede dudar es garai. Creo haber probado en FLV 2 (1970), 86 s., que gara (goara), garako, en ciertos empleos, no es otra cosa que el general gogara, gogarako, de gogo 'mente'. Ahora no excluiría en manera alguna la posibilidad de que Garagorri, Garate, Garibay vinieran sencillamente de garai más gorri, ate, ibai”.

11. Manterolak nahiago du sarohe/saroi kontuan hartu eta çelahe/zelai bikotea dagoela pentsatu. Orpustanek irekirik uzten du gaia: “... à Larcevau 1412 çele dont l'apparentement à zelhai (...) ou même au navarro-castillan médiéval sele 'pâturage' reste incertain" (2000: 283). 
aurkitu ditugu X / X + -bi egiturakoak (cf. §11 iztai < *izter-bi-z) eta, beraz, lehen baino askoz seguruagoa dugu -bi hori benetako morfema zela eta ez hondar huts. Bi osagai honen inguruan antolatuko dira hurrengo orriak.

\section{Ez 'chemin', 'franchissement' baizik}

(5) "Il s'agit, par la comparaison et au moyen d'une analyse diachronique, de faire apparaître une signification là où, au départ, nous n'avons qu'une désignation. La dimensión temporelle devient ainsi une dimensión explicative" (Benveniste 1969: I, 11-12).

Nahiz aurrekoak ere zerbait badiren, proposatu etimologia aldaketa txikiaren (hibai < *hur-ban-i $\rightarrow$ hibai $<i b a h i^{12}<$ *hur-bar-bi) hobari nagusiak beste nonbait dira. É. Benvenisteren "Problèmes sémantiques de la reconstruction" bikaina irakurtzen ari nintzela — de Lamberterie 2000ko iruzkin jakingarriek eraman ninduten hara-, ohartu nintzen bazela han zer ikas eta zer mia, egile horren lan zoragarri orotan ohi legez. ${ }^{13}$ Etimologia egokien baldintza orokorrak erakusteaz gain - "motibazioa" bilatu beharra eta "deizio" / "esanahia"-ren arteko oinarriko bereizkuntza, esaterako-, hor Benvenistek indoeuropar (IE) hitz-familia zenbaitez egin argiak euskarazko ordainetan ere argirik egin diezaguke menturaz. ${ }^{14}$

Gure egungo egitekoari artez lotuaz, IE hizkuntzetako lekukotasunen ezagutza eta miaketa paregabearen bitartez, Benveniste ohartu zen lat. pons 'zubi', grek. póntos 'itsaso', arm. hun 'ibi' eta avestiko panta 'bide' — dakienak antzeman dezakeen aitzin-forma batasunaz landara (homologiaz, zehatzago)—, esanahi zaharrago bakar batera ere eraman litezkeela. Esanahi zaharrena 'bide'-k dirudien arren, 'franchissement', 'igaro-bide' litzateke egokiago, eta hortik neke handirik gabe erator litezke ondoko adierak oro:

(6) “...il n'est pas simplement le chemin en tant qu'espace à parcourir d'un point à un autre. Il implique peine, incertitude et danger, il a des détours imprévus, il peut varier avec celui qui le parcourt, et d'ailleurs il n'est pas seulement terrestre, les oiseaux ont le leur, les fleuves aussi. Le pánthāh n'est donc pas tracé à l'avance ni foulé régulièrement. C'est bien plutôt un "franchissement" tenté à travers une région inconnue et souvent hostile, une voie ouverte par les deux à la ruée des eaux, une traversée d'obstacles naturels, ou la route qu'inventent les oiseaux dans

12. Aurreko zenbait lanetan izartxoarekin berreraikitako formatzat erabili izan dut *ibahi, *hurban-i zaharrago baten [orain *hur-bar-bi] eta hibai historikoaren arteko pausutzat; J. Manterolari esker jakin izan dugu — bai nik eta baita bestek ere- izartxo horretaz arindu dezakegula, lekukotua baita. Bidenabar, Lakarra 2009/2013 eta ondoko lanetan aztertu ditudan ${ }^{*} h_{3 / 2}>h_{1}$ bilakabidean orain nahiz -n- > - h- nahiz $-r>-h$ sailetariko hasperenak aurki ditzakegu.

13. Cf. Watkins 1984 Benvenisteren ekarpenaz, bereziki haren IEko erro-teoriaren inguruan; bidenabar, haren indoeuropar erakundeei buruzko liburua inoiz egindako lan etnografikorik bikainena iruditzen zitzaion. Urruti gara Euskal Herrirako antzeko ezer izatetik

14. B zaharrean gertatzen den aretx 'chêne' / aretx 'arbre' grekera zaharrean ere gertatzen da; are interesgarriago iruditzen zait 'arbre' = 'fidélité' erro beretik IE hizkuntzatan: cf. iritzi <e-reitz-i (< *len-i-z-) / hareitz, lizar (<*(e)-len-iz-), edo zuhur (<*zur-hor?) / zur (beharbada konposizioko $-n>-r$-rekin, zuhur-ek bokal sudurkariak baititu); ikus Benveniste 1954: 299 hh. 
l'espace, somme toute un chemin dans une région interdite au passage normal, un moyen de parcourir une étendue périlleuse ou accidentée. L'équivalent le plus approché sera plutôt "franchissement" que "chemin", et c'est bien ce sens qui explique la diversité des variantes attestés" (Benveniste 1954: 297-298: etzanak nireak dira [J.A.L.]).

Nago hori bera gertatu dela euskarazko goiko *bi horiekin eta baita ondoren datozenekin ere, bide eta honen eratorriak barne.

\section{4. -bi gehiago}

Lakarra 2010n proposatu genuen bi-ren esanahirik zaharrena ez zela '2' eta hasiera baten izen eta adjektiboen eskubitara zihoan morfema hau ${ }^{*}$-bi batetik $\left(<{ }^{*}\right.$ gwi $<{ }^{*} g_{0}(n) i$-tik alegia) atera zela: hasteko, ${ }^{*}$-bi hori dugu bai ibi eta zubi-ren bigarren zatia (Mitxelena 1973: s.u. ohartu zen horiezaz, Orpustanek, aldiz, "...zubi vraisemblablement composé sur ibi" [2000: 244] dio) eta baita azpi-rena ere (honetaz ez), aurretik hur, zur eta hatz direla, hurrenez hurren, cf. Lakarra 2010: \$28. Orain '2' ez diren -bi-en lehengo zerrendatxo horri beste zenbait gehitu ahal dizkiogu (gogora \$2): hibai bera eta bizkai, gutxienez, (baita, agian, aldai, zumai, sabai eta zelai); baina badira gehiago.

Gure 2010eko proposamen hura ulertzeko behar da buruan izan (cf. §1) —baina lan horretan erakutsi bezala, hori berori gertatzen da egungo zein antzinako hainbat hizkuntzatan-kontaketa, hatz lodia alde batera utzi eta albokotik hasten zela: eri luzeena, erdikoa, aldi berean 'bi(garrena)' da kontaketa molde honetan eta baita 'gorena' ere, beraz; cf. Epps 2006.

Erbi-rentzat jatorri zeltikoak aipatu izan dira apud Mitxelena $1964^{15}$ eta baita liebreren familia ere ("Liebre-ren familiako kideren bat" datekeela diosku Mitxelenak berak, baina zehaztasun gehiagorik gabe). ${ }^{16}$ Areago dena, Corominas-Pascual-en eta Rey-ren hiztegietan ez

15. Zeltiar mailegutzat emandako zenbaiten garbiketa egin ondoren “... quedaría con todo una lista bastante larga de otras propuestas, mejores o peores. Citaremos entre otras que podrían entresacarse, vasc. erbi 'liebre' : irl.ant. heirp 'dama, capra', de *erbhi- [oharrean: "Holmer presenta un paralelo para salvar la diferencia de valores"]" dio. Agud-Tovarrek, s.u., "Mich. Pas.Leng. 144 compara..." dakarte eta — Mitxelena hil eta urte batzuetara— "Podría compararse con" OEH-k s.u., labur eta esanahi ezberdintasuna ere markatu gabe. Baina ez da zehatz-zehatza, konparaketa — "hobexeagoa edo okerxeagoa" — lehendik baitator, eta ez baitu Mitxelenak plazaratzen eta ezta aldezten ere. Arbelaizek, egokiago, "cita la hipótesis" dioelarik soilik. Are gehiago, "al lado de tanta crítica —negativa, aunque quizá saludable — de propuestas ajenas, permítasenos presentar una de propia cosecha" (nire ustez) argi-xamarrarekin hasten du Mitxelenak pasarte horretako hurrengo ahapaldia eta, dakidala ez du latinaurreko mailegutzat ondoko lan bakar batean ere ematen; Gorrotxategi 1987k ez du aipatzen, ez alde ez kontra egiteko.

16. Esan bezala, ez dut aurkitzen erbi-ren forma azal lezakeen ezer ez Ernout-Meillet, ez Corominas-Pascual ez Rey-ren liburu bikain ezagunetan; bada, haatik, azkenengoaren hasieran interesgarri izan litekeen ondoko oharra: "Ce mot est d'origine méditerranéenne : il n'existe pas de nom indoeuropéen du lièvre, probablement parce que l'animal était tenu pour de mauvais augure, et qu'on évitait de le nommer". 
dut ikusten zein izan litekeen kide hori eta ezta hurbileko edo urrutiagokorik ere; markagarria iruditzen zait, gainera, Euskal Herri osoan lehen kontsonantean nahiz barnekoan jatorrizko ahoskabea gordeko lukeen aldaeraren alerik ez izatea. Aldiz, *heri- (zein erhi) + -bi-tik abiatuaz arazo formalak oro desagertuko lirateke, eta semantikaren aldetik, erbien ibilera eta oinen egitura ezagutuaz ‘*erhi-gainean' ez genuke desegokiegi. Gainera, eta hau aurrekoa bezain garrantzitsu iruditzen zait, erbi-ren osaera, gainera, aurreko eta ondoko -bi izenenaren pareko genuke: X-bi, "x" hori delarik igaro-bidea edo gainditzeko, zeharkatzeko modua. Ikus atal honen akabuko Benvenisteren aipua IE hizkuntzetako egoeraz eta euskarazko paralelismoekiko oharrak.

Orbi "1. galop ou course" eta "2. poste, vereda" dakartza OEH-k, hurrenez hurren, Oihenartek Pouvreauri bidali oharretarik eta hiztegigile horrek Etxeberri Ziburukorengandik hartutakoetarik. ${ }^{17}$ Mitxelenak FHV-n (412) eta enparauetan bide > *-bie > -bi bilakabide-aukera aurkezten du ${ }^{18}$ baina ez da horren beharrik Benvenisteren goiko aipua gogoan: "C'est bien plutôt un "franchissement" tenté à travers une région inconnue et souvent hostile...", batez ere horko "un moyen de parcourir une étendue périlleuse ou accidentée". Hots, orbi $\left(<{ }^{*} \text { oin-bi }\right)^{19}$ : erbi $(<*$ erhi-bi) : azpi (<*hatz-bi) : zubi (<*zur-bi), etab., dagoeneko ikusi bezala.

Zerrenda honi dagokio, beharbada, garbi ere; §2n ikusi dugu dagoeneko garai-rekin egingo lukeen bikotea [*X-(bar)-bi]. Horren lehen zati litzatekeen gar-i buruz, EHHE-n azaldu bezala, gar erroaren eratorri eta ondorengoak 'gari' nahiz 'galdu' adieraztera iritsi ziren, *ter erroak IE familiako zenbait hizkuntzatan legez (latinez eta grekeraz / errusieraz, hurrenez hurren). *Gar 'araztutako' + goi 'lurra, behea...' $\rightarrow$ garbi 'araztutako', 'aratz' bilakabidea izan bide dugu. ${ }^{20}$

Aurreko atalean eta honetan aztertutako berben azalpena bat doa Benvenistek 'bide'ren IEko familiari eman azalpenarekin; hara, beste modu batera esana §3n ikusi duguna:

17. Bietan ere forma mugatuez ari gara eta forma biluzia orbi dugu. Bada beste orbi bat — sarrera berezia eman zaio OEHn—, Mongongo Dasanzaren pasarte ulergaitz batetik aterea: "Kolika bezala heldu da eritarzun hura eta hala katolikarentzat on diren erremedioak balia daitezke sabel minetan, bai eta ha[la]ber briga eta orbietan".

18. Cf. "...-bi, al parecer variante de bide 'camino' en último miembro de compuesto" (Mitxelena 1958: 102).

19. Cf. orpo < *oin-bo eta OEH s.u. orbide: "onbidia edo oinbidia".

20. Arbi Lakarra 2015a-n mailegu gaskoitzat jo arren, ez nuen asmatu, ez bainituen behar bezala pisatu, 1) hor soilik "Bay[onne]" zekarrela Simin Palayk (OEH-ren arabera orokorra da euskaraz) eta, beraz, alderantzizko mailegaketa arrazoizkoagoa dela, 2) gaskoiz soilik "navette" dela, euskaraz beste hainbat adiera dituelarik, eta 3) euskaraz $h$ - gorde (ez gehitu) duten lekukotasunak (harbi) hainbat direla gutxiengoan izan arren; gaskoiz ez du etimologia argirik, ez eta kiderik gainerako erromantzeetan.

Antzeko arrazoiak aurkez litezke horrekin batera bildu (h)erpin-en jatorria ere euskarazkotzat izateko eta ez gaskoitzat; honetan, gainera, lehen osagaia (*heri/erhi-) ezagun eta argia dugu harbi-n ez bezala: hobeto esan, har- horrek harri dakar gogora, noski, baina nola azal hitz osoaren esanahi hori? 
(7) "À partir de skr. pathya et dans l'histoire de l'indoaryen, nous avons "chemin ", mais ce sens n'est pas plus " originel "que les autres; ce n'est qu'une des réalisations de la signification générale ici définie. Ailleurs, ces réalisations sont représentées autrement. En grec, le "franchissement" est celui d'un bras de mer (...), puis plus largement d'une étendue maritime servant de "passage " entre deux continents; en arménien, d'un "gué "; et en latin, pons désignera le "franchissement " d'un cours d'eau ou d'une dépression, donc un "pont". (...) "chemin ", "bras de mer ", "gué ", " pont ", sont comme les variantes d'une signification qu'ils laissent reconstruire, et que le problème ne concerne pas l'aspect sémantique du terme dans telle ou telle langue, mais qu'il se pose pour chacun d'eux et pour la famille entière dont ils sont les membres" (Benveniste 1954: 298 [etzanak neureak, J.A.L.]).

Alegia, delako 'igaro-bidea', 'zeren bitartez', 'zeren gainetik', 'non zehar'... modu ezberdinetan gauzaturik edo zehazturik dugu, euskaraz bezalatsu.

\section{B(i)- zenbait}

Ezinbesteko da $b(i)$ - zenbait miatzea haren lehen zatia aztertu eta ibi, zubi, azpi, eta gainerakoen eskuineko osagaitzat isolatu ${ }^{21}-b i$ 'goi, gain'-ekin duena homofonia hutsa baino gehiago ote den erabakitzeko. Azterkizun berri horietarik, beso $-<* b(i)-e$-so $\left[<{ }^{*} b i\right.$ esk(u)-so] (ikus 45. oh.) — analizatu dut lehenago, cf. Lakarra 2013b: §6, TO SAY aditzaren gramatikalizazioaz aritzean. Hitz honen eraketa-paralelismoez IE hizkuntzetan, bistakoak dira, batez ere grekoz (Lamberterie 2000: 125-127); bietan konparazioak dira besoaren eta besaurrearen artean ("luze" / "labur" grekeraz, X / X-so 'handiago' euskaraz). Izan ere, konparaketaren hau bide zen euskara zaharrean -so atzizkiaren balio arkaikoena, cf. 30. oh. Eskuaren bi zati nagusien arteko erlazio edo konparazio horrek beso etimologikoki '*goiko esku handiagoa' (= 'eskuaren goiko parte lodiagoa') azaltzea zilegiztatzen du.

Begi-ri dagokionez, ohar bedi hori pluraltzat hartzeko, nahi eta nahi ez, begiak bihurtu behar dela, bestela bietarik bat baitugu —ezkerra zein eskubia, baina bat—, gizakiek eta beren hurbileneko animaliek dituztenak ezin baitira batera aipatu singularrean. ${ }^{22}$ Hori bera gertatzen da beso-rekin ere, jakina, baina ez buru-rekin eta ezta, itxuraz, —ikus beherago (§9)— bihotz-ekin ere: hots, gizaki bakoitzak hauetarik bakarra du eta ez da modurik bi '2'

21. Zehatzago, -bi isolatua dakusagu Mitxelenaren aipatu lanean (1973: s.u.); alabaina, ez da hor '2' eta 'goi'-ren arteko loturarik eta, gainera -bi *-bide-ren laburtzapentzat aurkezten da (cf. 17. oh. eta dagokion testua). Ezta ere bi horrek aurrizki edo erro bezala izan lezakeen erabilerazko inongo oharrik. Cf. §4 orbi-ri buruzko ahapaldian.

22. Cf. Corbett 2000: 40hh bereziki zenbaki sistemen unibertsalez; hor ikus litekeenetik egiantz urria luke euskarazko dualak oraindik pluralik ez zenean, nabarmena baita hau berria dela, nahiz IS-n nahiz AS-n.

Uhlenbeck 1949: 111k ez duala baina posesiboa edo klasea du nahiago $b$ - horrentzat (= inper. b-, bera, bere); bare, barrabil, beatz, beazun, begi, beharri, bekoki, belar, beso, bidar, bihotz, biri, bizar, bizkar, bular, buru eta buztan kokatzen ditu zerrendan; kanpo uzten ditu —horiekin aurrizki posesiboa ez duelako egiantzeko aurkitzen— behor, behi eta belar. Ez ditugu oraindik guztien etimologiak baina Uhlenbecken zerrenda horren batasunak egiantz gutxi du. 
horiek izan daitezen. Noski, gure azalpenean lehen esanahia litzatekeen 'goi' itzaltzean eta bere balio zaharra atzentzean, ' 2 ' berriagoarekin lotu dira familiako hainbat hitz, bi direlako begiak eta beste zenbait gorputz atal, edo beste zenbait bakarrak izan arren (bihotz) bi parte dituztela pentsa daitekeelako, demagun.

Halere, begi-n bi- '2' edo "dualtzat" ez hartzeko —euskalaritzan noizbait egin izan denaren aurka - badugu arrazoi parea behintzat: bata, orokorra (eta gorputz-atal guztien izenekin balioko lukeena, besteak beste), zenbaki hori IS-aren eskubitara jartzea zelako usadio orokor zaharrena: ${ }^{23}$ toponimian Bidebieta edo Urbieta-ren tankerako asko da, baina **Bibide (e) ta edo **Biureta gisako alerik ez; gehi bekio '*goi' antzinako esanahia, aldiz, ongi egokitzen zaiela, bai begi eta baita beso-ri ere, eta, beharbada, beste zenbait $b(i)$-ri gorputz-atal izenon artean — eta hortik landa—, gorago eta beherago ikusi legez. ${ }^{24}$ Begi *bi 'goi' + -hegi-tik abiatzea proposatzen dugu, beraz — cf. adar + hegi > adegi, izter + hegi > iztegi gorputz ataletarik atera gabe- beso-n bezala, *bi behin-behineko CV erro-egitura higatu edo aurrizki horretatik.

\section{Bide}

Mailegu latindar, erromaniko nahiz kamito-semitartzat hartu izan da bide (cf. Agud $\&$ Tovar, s.u.), nahiz beti argudio ahulekin izan. Mitxelenak ez zuen ezer garbirik esan gai horretaz, baina bai, aldiz, via ad Oiasso-tik azal litekeela horri lotu Bidasoa, Mitxelena 1973: s.u. bide). Izan ere, bide TVTV egiturarekin nekez izan zitekeen AE zaharreko nahiz AE modernoko erro soila —cf. Lakarra 1995, 201 la, etab.- eta, bestalde, ez genuen ez bi- eta ez -de ustezko osagaientzako azalpen egiantzekorik; hortik aurreko lanetan bide mailegutzat jo izana. ${ }^{25}$

Baina hitz hori eta beste zeinahi osagai txikiagotan azaltzean, guztia aldatzen da zeharo. ${ }^{26}$ Egun, bide-ren inguruan bestelako analisi landuagorik gara liteke, noski: aurreko hitzetan bi- osagaiari enparatuetan -bi-ri aitortutako egiteko bera ezagutu diogu eta -de ere morfema ezaguna dugu edo, hobe, Trasken legea erabiliaz, atzizki ezagun baten forma ez hain

23. Bestalde, horrek sendotu egiten du $b i<{ }^{*}$ gon-i azalpena, partizipioak (eta hortik atera adjektiboak) eskubitara kokatzen baitziren; B-ko bi bider salbuespenaz ikus 31. oh.

24. Ez nahi eta nahi ez gainerako guztiekin, ordea; bidenabar, seguru ote gara ez ote den mailegu bakar bat ere tartean (cf. belaun)?

25. Ikus Mitxelena 1963 forma kanonikoa lanabestzat hartuaz egin azterketetan oinarrizko irizpide eta ondorio hauez; bide-ren gainerako "zatikatzeak" (**b-ide, **bid-e, ${ }^{* * b}$-id-e, demagun) hizkuntzaren fonotaktikaz dakigun guztiaren aurka doaz, —harako Boudaren "colliers" direlako haiek bezalatsu edo. cf. Lakarra 2003/2008-, bi-de-k baino azalpen diakronikorako aukera gutxiago izateaz landa.

26. Hori bera gertatu zen lehenago edo geroago *ardano, bazter, izter, etab.ekin (eta antzera gertatuko bide da etorkizunean) ere. Gogora bedi forma kanonikoak ez duela etimologia zehatzik ematen, baizik eta azterketa berrien beharra bistaratzen, cf. Lakarra 2008 eta Mitxelena 1963, eta horretara —noiz aski, noiz gehiegi—akuilatzen. 
ezaguna. ${ }^{27}$ Alegia, *den 'FINISH'-en gramatikalizaziotik sorturiko (cf. Lakarra 2013) nahiz pluralaren ("igarobideak"), nahiz aditz-ekintzaren ("igarotze") alomorfo zaharra komeniko litzaioke bigarren parte horri. Alde-ko -de (cf. FHV 354-355), handi edo hordi-ko -di edo ezkerdo, ugerdo-ko -do bezala, forma sparita, gutxiengo erabatekoan edo galtzear den alomorfo zaharra dugu; bertatik datoz historikoki bananduak diren -te 'ekintza' / -te ' 'plurala' esanahiak (cf. etorte vs. dute), nahiz badiren aztarnak lehenago frango hurbilago zirela: gosete, urte, bete (< *bat-te), elurte; egun ere, "atzoko elurteak elurtza handirik ez du utzi" zilegi da, etab. ${ }^{28}$

Hemen sakontzerik ez dudan arren, markagarri iruditzen zait Trasken goiko formula (cf. Lakarra 2015b) etimologiagintzan duen bistako garrantziagatik, eta are gehiago gramatikalizazio-kateak goragotik hartuaz — jatorri lexikotik hurbilago- zabal bagenitza: CVC > CV (> V / C). Hots, ertzetako kontsonante bana eta tarteko bokala zuten gutxieneko erro lexikoek (cf. Lakarra 1995hh) —baina ez gramatikalek eta fonosinbolikoek- eta gramatikalizazioaren bidez morfema bilakatu zirenek prozesuaren akaburantz eskubiko kontsonantea galtzen zuten. Honen adibide dira *nin $>{ }^{*}-n i$ (part.) $>i-/-i($ dat.) edo *dar $>$ da(ASP indet.) / -da (alatiboa) > a (id). Beraz, "Trasken legea" (-DV > -TV/-V) CVC > CV honen garapen berankor baten azpimultzo genuke. ${ }^{29}$

\section{Bide-ren eratorriak}

Euskal hiztegia-n (Sarasola 2005) b- letrako hitzak ikuskatzean bidaso-rekin —'ibai txikia', dagoeneko Etxeberri Ziburukok lekukotua - egiten da topo eta OEH-n Duvoisinen ahapaldi zabala dator, bidasoa ez dela izen propioa esanaz:

(8) "Le nom de la Bidassoa n'est pas un nom propre en basque, comme beaucoup l'ont cru ; on s'aperçoit au langage des paysans qu'ils l'emploient en qualité de nom commun, par exemple quand ils disent: Bidaso hori".

Mitxelena 1973k, s.u. bide, delako erabilera hori Bidasoa ibai ezagunetik bertatik

27. Ez dut orain *d->l- bilakabidearen bitartezko alomorfoen kidetasunaz jardungo, ez eta honek (gehi gi- / -ki, za- / -za eta gainerakoek) lagundu aurrizki $\rightarrow$ atzizki aldaketaz; ikus Lakarra 2006a eta hh.

28. Lakarra (2013b)-n aipatzen da Zavalak (2006) deskribatu 'finish' $\rightarrow$ iragana / 3.p. gramatikalizazioa. Besteren batean 'finish' $\rightarrow$ ekintza bilakabideaz beharko genuke hitz egin, euskaraz -te, -tze, -eta aditz izenetako atzizkiak kontuan izanik; nolanahi ere, badirudi inesiboa dela aspektu indeterminatua ematen diona perifrasiari.

29. Horrenbestez, Manterola 2015k arrazoi osoa du 3. graduko erakuslea ha (izartxorik gabe) berreraikitzean eta ez *har/har- gainerako gehienok orain arte egin dugun bezala. Pentsatzekoa da lehenago kategoria lexiko batetik (seguruena har 'hartu'-tik, cf. Lord 1993) datorren neurrian $-C>-\varnothing$ gertatu dela, eta -C hori -r izan zitekeen. Erants bedi ha-tik har-azaldu behar badugu eta ez alderantziz, enbor bokalikoetako - $r$ epentesiarekin lotutako hedadura baten aurrean garela, ez soilik mugatuan (besteari, bestearen...) baizik eta lehenago mugagabean ere (besteren, besteri, bestera...). Ikus Lakarra prest.-2. 
gertukoa delako kontrakoa defendatu arren, behingoz baliteke kapitainak arrazoi izatea, ibaiek usuenik ez baitute izen propiorik ingurukoentzat, urrutiagokoentzat baizik. Horrenbestez, bidaso deitu bide zioten beren inguruetako ibai-zatiari (ez gogotan ez zuten osoari) Bidasoa aldekoek, hortik gertu beste hainbat ibairekin gertatu bezala, ${ }^{30}$ nahiz bidasoa ${ }_{2}$, bidasoa ${ }_{3}$, etab. ez iritsi arrazoi historikoengatik (ez hizkuntzazkoengatik) inoiz Bidasoa izatera; artikuluak ere ez du aukera handirik uzten.

Orobat, neke zait ulertzea —aipatu Mitxelena 1973ren, s.u. bi) Bidasoa < via ad Oiasso proposamenaren aurka - nola ez den beti garbi izan bidaso-n bide + -so-ren bilakabide erregularra dugula eta, beraz, 'erreka txiki' esanahia '*bide handi'-tik eta lehenago, '*bide moduko', 'bidearen antzeko'-tik datorrela, cf. Lakarra 2013b. Honela, nabarmenago egiten dira euskaraz eta indoeuroperaz hitz-familia honek dituen antzekotasunak: lehen aski garbi frogatua ez balitz, orain aitortu beharko genuke IE-n bezala, 'bide' esanahia baino sakonagokorik bazela bide-n: *bi 'goi' + *de 'ekintza', Benvenisteren harako 'franchissement' hura bera, hain zuzen ere.

Ohar bedi, dagoeneko eman arrazoiez landa, bidaso hitz zatikagarria izatea ere (eta are gehiago Bidasoa) Mitxelenaren argudiabidearen (< via ad Oiasso) aurka doala. Aurreko lan batean markatu genuenez, ${ }^{31}$ 'handiago' baino lehen 'pareko, moduko, antzeko' bide zen -so atzizki horren esanahia, laso-k oraindik gorde bezala: cf. dagoeneko RS 88 Olaso, guichi bazuc y laso, 'Olaso, pocos son como tú', etab. Nabarmena denez, defendatu nahi dugun 'bi(de) ':: 'ibai' : 'zubi' : 'ibi', etab., are gardenago egiten da bidaso-ko -so hori konparatibo huts gisa ulertuaz ('bide moduko' eta, hortik, 'bide handi'; cf. aitaso 'grand-père' eta gainerakoak); gogora, orobat, i-ra-go > igaro, eta Lakarra 2015a: \$3.1.4-n aipatu -ago ere (< *ha-go), Carol Lordek (1993) eta bestek 'TO PASS' aditzaren bitartez azaldutako konparatiboa, hain zuzen.

Familia osatuaz joateko, bider Mitxelenak "derivado de bide 'camino"' dela diosku eta, orobat, "irl. ant. sét 'camino', galés hynt, etc., gót. 'vez' (ainamma sintha- 'una vez', etc.)" azaltzen (FHV 49. oh.). Egile berak markatu legez (OOCC VII, 418), bider oso irregularra da deklinabideari dagokionez eta ez du bestelako atzizkirik ere hartu ahal: cf. aldi (aldiko, aldiz, alditan, aldirik...). Irregulartasun horien arrazoia bukaerako -r eranskintxo azaldugabean bide datza, baina Mitxelenak ez diosku ezer horren jatorriaz. Hoberik ez okerragorik aurkitu ez eta *bide-ar (i) izan genezakeela pentsatu izan dut inoiz, baina ez esanahiak eta ez formak ez naute asebetetzen.

Beharbada, hobeko dugu antzeko zenbait amaiera biltzea, argi bila edo: bazter, laster, izter, esaterako. Izter gerorako utziaz (\$11), laster dugu errazena: hemen lats 'ibai txiki' dugu, eta bigarrena -ber <-behera (cf. gazt. rápido). Bazter-en bigarren osagaia bera izan liteke, baina azkenengoan bider $<$ *bide + beher (a) fonetikoki egokia izan arren aski bide litzateke *bide +

30. Bidasoa ibaiak berak Baztan du izena Donezteben sartu baino lehen, J. Manterolak gogoratzen didanez.

31. Aditzaren gramatikalizazioaz (TO SAY) eta, zehatzago -so atzizkiaz eratu izen gehiagoz ikus Lakarra 2013b: atso, otso, baso, itsaso, beso, etab., familia-izenetako amaso, aitaso, alabaso eta enparatuez landara; jatorri berekoak ditugu oso eta laso gonbarazio-partikulak ere. 
-ber-ekin. ${ }^{32}$

Bestalde, bazter < prasepe proposatu ondoren, *uazter < *hur-az-beher(a)-ra jo nuen. Berriro aldatu beharra ikusten dut orain, *huraz- horrek bi arazo bailituzke gutxienez: 1) esanahia, zergatik uraren erreferentzia hori, bestelako "bazter" asko direlarik (baita u(r)bazter, etab. ugari ere)?; 2) hori bezain garrantzitsu, gutxienez: *hur-az horrek * $(h) a z$ artikuluduna suposatzen du, baina bazter-ek itxura zaharra du eta beste edozein analisi hobetsi behar genuke (zazpi < *borz-az-bi baino *borz-zaz-bi bezala; ikus 49. oh.). Hortaz, -az- horrek ez artikulu baizik eta erro edo amalgamaren baten zati izan behar du: zergatik ez *bar-z-? *Barz $>$ baz- ez da batere arrunta, disimilazioz ez bada: cf. ezker < *her-z-bu-ger / esku < *her-z-bu eta eskuin < *her-z-bu-on(e). Azkenik, bazter [*bar-z-be(he)r(a)] ( $r$ disim.) : ezker (id) :: baso (*barso, $\left.{ }^{*} r+s>s\right)$ : eskuin $\left({ }^{*} r z C>s C\right)$.

Hemen amaituko nituen bider-ekikoak Iñaki Segurolaren laguntza bikaina izan ez banu: haren bitartez ohartu naiz OEH-ko bider, biderreko, biderre (t) an eta biderrez azpisarreretan badirela nire (eta, beste bide batetik, Iñakiren), proposamen honen alde egiten duten erabilera garbi askoak: Zumarragaren milla bider geiago, Lazarragaren oneinbat bider eriotzea / zerren emaiten didazu?, Otxoa Arinen zenbat bider, Mogelen irugarren, laugarren ta geijago biderrian, Añibarroren esaikezu... iru biderreko aldiz, Otxoa Arinen asko biderretan, edo Kardaberatzen zenbat biderrez. Nago hauek guztiek ere -ber-en alde [cf. $-r>-R$, haur $>$ gauR-en legez] eta -behera-ren aurka mintzo direla.

\section{Bide $_{2}$}

Euskal hiztegietan ez dut aurkitu (neure erruz, segurki) gure bide eta OEH-ko bide "partícula que se coloca delante de la forma verbal personal. Probablemente; seguramente; al parecer" delakoaren arteko loturaz ohar ez azalpen asebetegarririk. Bataren eta bestearen erabilera eta balio zenbaitetik atera ahalko litzateke (Agud eta Tovar ere konturatu ziren dagoeneko) ez dela homofonia hutsa; ikus, esaterako, hiztegi horretan bide izan-en pean bilduak. ${ }^{33}$

Ondorio hori sendotzera dator zuzen-zuzen Aikhenvald-ek bere Evidentiality-n era horretako partikulez dioskuna:

32. Ez nuke ahaztu nahi Azkueren ohar parea s.u. bidar (ohar bokalismoari) (gero OEH-n errepikatua): "El único numeral que se resiste a la palabra bidar es bat, pues se dice bein, behin en vez de bat bidar. (...) Se usa bi bidar, aun en B, en que bi es pospositivo, pero más acaso birritan (...)". Zergatik bider aurreko salbuespen hori? Nago horren etimologian ikusi dugun *-ber horrek badukeela zerikusirik (**bide bi ber zein **bide ber bi-k ezinezko dirudite). Antzekoa gertatzen da **batgarren-ekin (ez hogeitabatgarren-ekin) barruan daraman -barren zaharragatik; cf. Lakarra 2010.

33. Iñaki Segurolak diostan bezala, "azpimarratzekoak dira 'zuzen, arrazoizko, egoki' esanahien inguruan dabiltzan erabilerak: cf. 'arrazoi, motibo' adiera, EtxZib-en 'zuzen, justu' izond., bide izan esapidea, (bere) bidezko, bidez(ki), bidegabe, etab.: hor bide hitza badirudi 'bide zuzen/egoki' moduan harturik dagoela oinarrian...". Ikertzaile berak diosku 'dirudienez, segur aski' adieraz, "aditzak adierazten duena uste izateko BIDEA ematen duela, baina segurantziarik gabe". 
(9) "Locative and directional markers also give rise to evidentials. The inferential -lem in Meithei is an erstwhile directional suffix, Chelliah 1997: 224. Its directional meaning, lost from modern Meithei, survives in many other Tibeto-Burman languages. This suffix comes from the grammaticalization of a Proto-Tibeto-Burman noun *lam 'road, way' (details are in Matisoff 1991: 389-390). The auditory evidential marker -ke in Euchee is cognate with locative suffix ke meaning 'yonder', 'way over there'34 (Linn 2000: 318). According to Linn, the semantic connection between the two is to do with distance: 'the action is so far away that it can only be heard and not seen"' (Aikhenvald 2004: 275).

Bide-ri gorago (\$6) eman diogun etimologia gogoan — bi $\left[<{ }^{*}\right.$ goi $]+d e<*$ den 'FINISH’-, ez da ahazteko Aikhenvald 2004: 274k "a verb 'complete' or 'finish' may grammaticalize into a marker of perfect, and then become an evidentiality strategy" dioskula, hainbat hizkuntzatako paraleloak eskainiz.

\section{Bi- gehiago}

Ia ezinbesteko begitantzen zait b(i)- hitz zenbaitez isats labur bat, goian (\$5) hasi bidetik. Har ditzagun bihar, bihotz eta bihur, demagun: dakidala, hiruretarik batek ere ez du etimologia seguru-ezagunik; forma kanonikoari dagokionez, CVCVC horrekin [bi- aurrizkia + CVC erroa] egiturakotzat joko genituzke, ... maileguak ez badira bederen. Forma kanonikoetan "sinisten" ez dutenek ("denetarik dukezu Jaunaren ardantzean"), morfema soiltzat badituzte, esan ahalko/gogoko lukete -h- horien jatorriaz? Cf. Lakarra 2009/2013 hh. AE-tik zuzen-zuzen horrelaxe datorkigula defendatzen ez badute, jakina; esan gabe doa, zilegi luketela aukera hau, Mitxelenak /h/-aren jatorritzat eman lau sailak eta forma kanonikoari buruzko ezaxola eskuan.

Bistan da *VnV-tik etorriz geroz, ${ }^{* *} m$ - itxarongo genukeela (cf. mahai, mihi, mehe, etab.), eta ez egiaz eta benaz hor ageri den $b$-. Aldiz, forma kanonikoan oinarritu edo ez, azken zailtasun hori gainditzeko ${ }^{*} b i-C V C$ analisiak hobetsiz geroz, gutxienez bi- horren esanahia zehaztu beharko dugu, ez baitirudi bi '2'-rekin ari garenik. Noski, AE-tik horrelaxe datorrela dihardukatenek ez dute ezeren beharrik; alabaina, ordainetan, hemengo eta aurreko bi- eta -bi guztien artean soilik halabeharrezko (i?) hoskidetasuna antzeman ahalko dute, ez inongo funtzio edo esanahirik.

Goragoko ahapaldietan ikusitakoen ondoren, bururatzen zaidan beste aukera bat zera genuke, bi- 'goi, gain(etik)' ulertzea, ibi, zubi, hibai, azpi, erbi, orbi eta enparatuetan -bi-rekin eta beso, bero, begi eta bide-n bi-rekin egin legez: *bi-har-en '* goi har(tu)'-k ez dirudi guztiz desegoki, eguzki zein ilargi berriaz mintzo; ${ }^{35}$ *bi-hotz-en kasuan '*goi' ez da arazo ${ }^{36}$ eta -hotz-i dagokionez —nekez izan liteke tenperaturarekikoa—, *hoz > hozi 'ernamuina'-tik abiatuaz

34. Gogora bideren kide indoeuroparrentzako Benvenistek eman oinarrizko esanahia, 'franchissement', alegia (ikus \$3); erka bitez, orobat, testuko Linnen azken hitzak eta aurreko oharreko Segurolarenak.

35. Gogora cadu > gau (eta arrats < *e-da-ra-dats, gehi ing. fall 'erori' / 'udazken'.

36. Ezta '2' ere, jakina, gizaki edo animalien bihotzak bi zati edo alderdi baititu; alabaina, testuan eman -hotz-en azalpenak ez du zenbaki adiera laguntzen. 
(cf. gatz / gazi, hatz / hazi, §l0eko isats / isasi, etab.) — gogora landare eta fruituek ere 'bihotza' dutela - gure azalpena ['goiko aldean sortutako, garatutako'] ez zait guztiz arbuiagarri iruditzen. ${ }^{37}$

Bihur-en asebetetzeko argitasunik ez da (hitz hau begitantzen zait hiruretarik zailen), baina iluntasun erabatekoa urra bide liteke *hur-etik beharrean *hor-etik abiatuaz (*bihor): egia da FHV-n $u>0 / \ldots R$ bitartez azaltzen dela B bihor, baina *-hor-etik abiatuaz o $>$ u / iC_ez litzateke ezinezko. Semantikaren aldetik, '*goi-hur'-ek ez dit ezer esaten eta zerbait gehiago adjektiboetan batez ere—, '* goi-hor'-ek ['gorantz makurtzen dena' edo]: cf. *hazi-hor > hazkor $>$ hazkar (FHV 71) eta *zur + hor > zuhur (cf. 13. oh.); hortaz, '*(behekoa) gora(ntz) egin' edo balitz, ez da bihurtu-ren esanahitik urrutiegi.

\section{Gainerako *bi- zenbait}

Beharbada, konpli da gauzak hemen uztea, —gogora Malkielen "etimologistak jakin behar dituenen artean noiz gelditu da garrantzitsuenetarik", apud Watkins 1990_, baina aurreraxeago jotzeko apeta sortu zait. Gainerako b(i)- hitzetan asko mailegu (biluzi) nahiz eratorri-konposatu erraz (bitarte) eta interes gutxikoak ditugu, agian biguin, bihi, bizar eta besteren bat lekat.

Bigun < finu azaldu dut inoiz, Lakarra 2011a, etab., ustez eratorpen fonetiko egokia zuelakoan eta esanahiaren aldetik ere hurbil gelditzen zela; alabaina, CVnV monomorfemiko horrek ez luke beteko aurreko atalean bihar, bihotz eta bihur dela eta aipatu **b...n...- hori: alegia, ez bigun, baizik eta **migun edo beharko baikenuke. Bestalde, —eta hau are larriago eta ezagunago da (cf. FHV 103, 141 *uin > un bilakabideaz)—, hitz horren aldaera nagusia eta informatiboena (gogora B-n *ain > an, *uin > un bilakabideak gertatzen direla), biguin dugu, nahiz beharbada amaieraren sabaikaritze adierazkorra izan edo -e leku-kasuetakoaren berranalisia.

Aldiz, *bi + (C) un-etik abiatuaz azalpenaren alderdi fonetikoa zein semantikoa ('azal, gain', 'bera, ahul') hobetuko lirateke; zehatzago, *bi-bun-e(-an/-ko/tik...) > *bi.une > *bi.wen > biguin. ${ }^{38}$ * Bun horrek merezi du, zalantzarik gabe, guk orain eman diezaiokegun baino arreta gehiago, noizbait ez baita txikia izan bere pisua morfologian: artean erka bitez muno, muño < *bun-no/-ño, (g)une < *(b)un + -e [cf. aurre, atze, B gane, eki. Parise, etab.] eta baita larru [cf. *dar, adar, larri, jarri], barr-u [cf. barren, ibar, bizkar] eta gehiagotan, beharbada. Azkenik, ez ote hori bera ilhun-en bigarren osagaia (<*hil-(b)un?); cf. lat. aluu "ventre ou plutôt cavité intestinale (...) Se dit aussi pour uterus" (Ernout-Meillet, s.u.) > eusk. alu eta, agian, beherago

37. Bide batez, bihotz : hozi enbor amaierako afrikazioaren aldeko beste froga bat dugu (horrenbestez neutralizazioa ez da betidanikoa); orobat, AEZean lau txistukari eta sei ozenekin ez baina (AEMko) erdiekin aski dugula laguntzen du (cf. Lakarra 2011b).

38. Cf. Murubarren > Muru.arren > Murugarren eta *e-da-zun > *ezadun > ezaun > ezagun; bigarren honentzat Schuchardtek aipatu aditz gaskoiak, ez ditu ez $e$ - nahiz - $n$ zaharra azaltzen, besteak beste. 
bizar $\mathrm{CuV}>\mathrm{CV}$ bilakabideaz. ${ }^{39}$

Bihi-rentzat ere bi- horretatik abiatzeko aukera genuke, agian: garia eta gainerako landareen goiko partea dugu bihi, erroaz beste muturrekoa, alegia, eta horri eransten bide zaio ihi(n), '*buruxka' eginaz. Ihi-ren etimologia, ihintz-ena bezala, *nin 'eman'-ekin lotua bada dirudien legez —Mitxelenak 1973, s.u. 301 i, ihi "como la forma antigua de la base parece haber sido *ini..." dio—, '* goiko emaitza' edo genuke: *bi\#*nin-en $b$ eta $n$ morfema diferenteetan lirateke eta horrenbestez ez genuke ${ }^{*} b-n>{ }^{*} m \ldots$ bilakabiderik. ${ }^{40}$

Isats. Mitxelenaren Apellidos-eko sarreran "en cuanto a Isasi (...) aparte de isats, deben tenerse en cuenta otras posibilidades: en primer lugar la forma vizc. (variedad de Cigoitia) isasi 'jaro', que R. Lafon considera var[iante] de sasi, con el mismo prefijo que ibar con respecto a barr-en o barr-u (EJ 2, 367), o quizá también el participio itsa(t)si 'adherido, agarrado', sust. 'grieta', deitura zaharretako grafia exkaxak batera edo bestera jotzea ezinezko egiten omen duelarik.

Hasteko, nekez egon liteke ezer isats : isasi bikotearen pare, beren arteko erlazioa gatz : gazi, orratz : orrazi, hatz : hazi eta beste ( $\$ 9$ ko bihotz : hozi barne) aspaldiko egoeraren, oraindik erro edo hitz amaieran afrikatuak ez bakar ez nagusi ez zirenekoaren lekuko baita. Bestalde, nago isats eta itsatsi $-<*(h)$ atz $(e)$-jats-i, [cf. itzali $<*(h)$ atz(e)-jali, itzaungi $<*(h)$ atz(e)-edadongi, etzan/-in/-un $<*(h)$ atz(e)-edon eta itzuli $<*(h)$ atz(e)-eduli- segurtasunez bereiz litezkeela; ez beren kategoria gramatikal ezberdinak eta ezta 2. silabako frikari/afrikatuek ez dute behintzat alde egiten.

Lafonen goiko zatiketa ona bada i- ez bide da ez ibar ez $h$-i-bai ez gainerakoena, horietan hur baitugu oinarri eta ez dirudi horrelakorik dugunik isats-en. Hemen, aldiz, *(b)i-sats egoki litzateke, toponimiak eta hortik atera onomastikak 'retama, arbusto'-ren alde egiten baitute adiera zaharren gisa; beraz, '(lurraren) gaineko sasi' genuke lehenik eta berankorrago lirateke (metafora eta metonimiaz sortuk) 'erratz', 'buztain' eta enparatuak. ${ }^{41}$

Izotz, *hur-zotz-etik azaldu izan dut lehenago, Mitxelenaren *ihintz-hotz-ek ez

39. Orpustanek 2000: 151, 310-311 testuan aipatu zenbait alomorfo biltzen ditu, baina haien forma eta esanahi zaharra erabaki gabe eta murru (> mur) ere tartean sartuaz, egiantzekotasun gutxirekin, egia esan: "la base ancienne (renforcement de la vibrante) mur-/mun- et par dénasalisation bun... On ne sait si la base sans nasalisation bun- est la plus ancienne [bi aldetarantz gertatzen omen bilakabidea]" (151).

40. Beste aldi baterako utzi ditut testukoak baino askoz ilunago iruditu zaizkidan idun, ifar, ifini, igun.

41. Nahiz Mitxelenak azken erregela hau soilik o/u-ren aurrean ikusi, susma liteke itsaso-n nahiz $i$, nahiz a-ren aurrean gertatu dela, orobat arte-n: cf. ere < ber-e; are < thar-e (orain hobe *ha-r-e, ikus Lakarra prest.-2) antzekoa dugu baina honetan partikularen izaera enklitikoak laguntza berezia ematen dio galera horri eta ez da benetan hasiera absolutu garbian gertatua. Arte (< *barte) dela eta, cf. Egibar: Egiarte, Iribar: Hiriarte, Uriarte: Uribarren, etab. Ikus 43. oh. 
baininduen asebetetzen. ${ }^{42}$ Formalki ez litzateke arazorik *bi-zotz izan dadin eta are hobesteko ere iruditzen zait Corominas-Pascualek escarcha-z diotena ikusirik: hitz horrek ez du, dirudienez, etimologia argirik baina egileek erabilera zaharrak aztertu ondoren dioskutenez "está clara la comparación de una superficie o una labor escarchada [dulces esc. edo aguardiente esc., adibidez] con la escarcha que cubre el terreno". Ikuspegi honetatik *(b)i- '(lur eta landareen) azala, gaina', *hur baino egokiago genuke zotz horrekin konbinaturik eta goian isats-i eman azalpena ere alde luke, gutxi edo asko.

\section{1. (B)iz-}

Lehen (\$2) *hibar-etik hibai (*hur-bar $\rightarrow$ *hur-bar-bi) bezala bizkar-etik bizkai atera dugu: *biz-bar $\rightarrow$ *biz-bar-bi). Azken bi etimologietako osagaietan, bar-en familia lehenagotik genuen aski ezagun eta, halaber, orain -bi zein bi- ezagunago zaizkigu. Eta biz-? Hori argitzeko bada laguntza gehiago, bizkar eta bizkai landa.

Izter ${ }^{43}$ / iztai arestiko *biz-bar / *biz-bar-bi bikotearekin guztiz erkagarri iruditzen zaigu: ${ }^{44}$ hori bai, ez -bar : -bar-bi baina -ber : -ber-bi bide genuke. -Ber hori lehen laster eta bazter-en aurkitzen dugun bera izan liteke, *-behera alegia (ez bider-eko *-ber), bigarren osagaietako bokalarteko eta 3. silabatik aurreragoko azken bokalen erorketarekin. Labur, izter $<*(b) i z-$ be(he)r(a) dugu [gogora $\$ 7$ laster < *lats-be(he)r(a)], *biz-bar-en oso antzekoa, batean *biz= 'buru' eta bestean *biz = 'ipurdi' (gogora Z azpi 'ipurdi'), bietan *biz< *bi $(+-z)$ 'goi'.

Hortik dator, noski, iztegi ere, *izter-hegi-tik, *iztaegi-ren bitartez. Alabaina, 'ingle' eta 'descente, cuesta abajo' dator OEH-n iztai-iztei-iztegi-istai-istei multzoarentzat eta iruditzen zait batzuek iztegi-ren aldaera diratekeela, baina gainerakoak iztai < *izter-bi-renak.

Bizar < *bi + zar '*goian sortu (ilea)' — kokotsean eta masailean, alegia, ez bular eta anketan, demagun-, ez bide da defendagarri lehen hurbilketa gisa ere, egitura hain partikularragatik (ez dut aditz-enbor horrekin sortu antzekorik ezagutzen). Horregatik pentsatu nuen *bezu 'ezpain'-etik (erroman. bezo) aterea izan zitekeela, hots, *bezu-bar > *bizuar > bizar. Egia da hitz hori modu autonomoan ez dela inon lekukotua; alabaina, ezpainek ez du etimologia ezagunik eta baliteke hasierako ez- hori *bezu baizik ez izana: *(b)ez(u)+ gain [ala*(b)ezw-(g)ain > ezpain?], alegia.

Halere, bada beste aukerarik oraindik: bar-en C- > $\varnothing$ ondoko -ar-aldaera buruan (cf. arte [Iribar/Iriarte], cf. goiko zel(h)ar, garai, Muru.arren eta beheragoko izar), *biz-ar analisia zilegi litzateke eta horrek aurreko ahapaldiko gainerako proposamena ere merkatuko bide

42. "No sería con todo imposible que el común izotz 'escarcha', 'hielo', conforme a una opinión que se viene repitiendo desde hace mucho tiempo, viniera de ihi $(n) t z$, etc. "rocío' y $(h) o t z$ 'frío"' (FHV, 411) eta horrelatsu Orpustanek 2000: 172, 184, FHV-ren aipurik gabe. Alabaina, *ametz + heta > Amezketa eta *baratz(e) + hari > barazkari direlarik (eta ez **Amezeta, **barazari) egokiago iruditzen zait neure oraingoa, baita esanahiari dagokionez ere.

43. Dagoeneko Schuchardtek ikusi omen zuen (Agud-Tovar, s.u.) xixter-en $x$ - protetikoa dela eta ez zaharra. Antzekoak aurki litezke (t)xaribari edo (t)xorabiatu-n, gaskoitik *hV- egiturarekin hartutako bi mailegu baino ez aipatzearren, ikus Lakarra 2015a.

44. ${ }^{*} b->\emptyset$ gehiagotarako ikus 8. eta 47. oh. eta azken honi dagokion testua. 
genuke, ezpain-entzat *bezu ez baita aukera bakarra (*hez- ere egoki genuke eta horrelako zerbait behar dugu hezi, heze, eta agian eztul-entzat) eta, horrenbestez, aztarna gehiagorik gabe, baztergarri litzateke.

Itxuraz ezpain-ekin lotua izan litekeen eztarri-k ere etimologia falta du baina kasu honetan ez dut uste bezu-tik abiatu behar dugunik (zer genuke *-tarri?). *Hertz-te-harri-tik ez litzateke arazo formalik (ez semantikorik, gogra *sa-hertz > sahets): cf. *hertz-te-hari > estari eta hemendik gero (ez lehen) estali, bidari-tik (*bide + -hari) bidali bezala. Lehen kasuan disimilazioa dugu eskubiko -rr-arekin, bigarrenean $r z t>r s t>s t$ taldearen bilakaera arrunta. Bikote berdintsua dugu ezker / esku(b)i-n ere: *hertz-bu(n)-ger / *hertz-bu(n)-hon(e); ${ }^{45}$ ohar bekie bi bikoteetan $z / \mathrm{s}$ txistukariei, disimilazioaren edo taldearen bilakabidearen arabera. ${ }^{46}$

Iz- hasten diren zenbait hitz izan litezke *biz- (hots, *bi-z) hasierarekin lotuak; esan gabe doa, ez da guztietan segurtasun bera:

-izpi: OEHek 1. 'brizna, hebra', 2. 'rayo (de luz)', 3. 'poco, ápice'; *bi-z-bi, 'axal-axaleko' edo? Literalki gain-eta-gain, erreduplikazio antzekoa baina lotura morfologikoaz?; cf. lehen (\$2) *bi-z-bar-bi > bizkahi > bizkai eta kate bereko *hur-bar-bi > hibai / *hur-bi, etc.

-izar-en kidetasunak badu zailtasunik: *(b)iz-(b)ar >izar izateko bi *b- > $\varnothing$ onartu behar dira —bada, halere, horrelakorik, cf. goian 8 eta 43. oh. eta \$2ko zelai, zumai-; halaber, goiko *biz-bar > bizkar-ek beranduago berregina edo behar luke. Hori bai, semantikari dagokionez 'goi', 'goian', 'goiko' ulertzea 'izar'-ek beste ezerk baino errazago luke; cf. 'izarr littéralement 'étoile' utilisé par extension de sens comme oronyme 'hauteur' (Içarbe, Içarlegui, etc.)" (Orpustan 2000: 154).

-izerdi-n —ipurdi-n gertatzen zenaren aurka (cf. §1)—, -erdi hori ez bide da "geografikoa" edo "kopurukoa", bestea baizik: 'goitik, gainetik egin(dako)', 'bustitako' edo uler genezake; gogora bedi landare eta harriak ere izerditzen direla. Tovarrek lehenik eta gero Mitxelenak gogoratu dute, latineko paralelismoarekin erdi eta $_{\text {erdi }}$-ren arteko lotura (ikus OEH eta Agud-Tovar s.u.).

-izorra-k —Agud eta Tovar horretaz ohartu ez arren—, ${ }^{47}$-a itsatsia du OEH-n eta hori ezinbesteko du gure proposamenak: gogoan hartzen badugu "a" eta "o" bokalen arteko metatesi zenbait (joan $<{ }^{*} e$-da-non, esaterako) eta atal honetako kideetan aurkitu $* b->\varnothing$ bilakabidea erantsiaz, zilegi litzaiguke *bizarro-ra iristea (*biz-arro-ra, alegia). Haurdun edo "esperantxan direnen" gorputz-aldaketez (batez ere "goitik", gerritik gorakoetan) aritu beharrik ez da: aski

45. Lehenago *hertz-gu(n)-ger / *hertz-gu(n)-on(e) eman izan dut baina batera zein bestera -u, -une, gune-ren alomorfo izanik hobe dugu batean $-b u->-u$ (eta gero $-u>\emptyset$, 1. osagaiaren 2. silaban izanik) eta bestean ${ }^{*} r z(u)-h>s k$; honela ez dugu -gu- alomorforik suposatu beharrik.

46. Sustrai-rentzat ez da batere garbi -bi behar dugun, eta agian aski genuke suster + errai-rekin.

47. Beti bezala, hiztegi horretan ezertarako ez diren hainbat "proposamen" biltzen dira; bat (*i- + zor 'doble', cf. zortzi) Lafitteren izenean jartzen dute baina ez dut zuzenean ikusterik izan erreferentzia gaizki dela baitirudi. 
bide dugu Urtsuaren kantuko 'kotillona labur duzu' eta antzerakoak gogoratzea. ${ }^{48}$

Akaburako utzi dut agian norbaiti lan honetan aipatuetarik interesgarrien irudi lekiokeena: bizi, alegia. Labur, horren analisirik errazena bi-z-i-k dirudi —erroa, instrumental / soziatiboa ${ }^{49}$ eta partizipioa-; balio semantiko zaharrenari doakionez, ba ote horrentzat goian (\$3) bildu dugun pántah avestikoarekikoa errepikatzea baino hoberik?

(10) “...il n'est pas simplement le chemin en tant qu'espace à parcourir d'un point à un autre. Il implique peine, incertitude et danger, il a des détours imprévus, il peut varier avec celui qui le parcourt, et d'ailleurs il n'est pas seulement terrestre, les oiseaux ont le leur, les fleuves aussi. Le pánthah n'est donc pas tracé à l'avance ni foulé régulièrement. C'est bien plutôt un "franchissement" tenté à travers une région inconnue et souvent hostile, une voie ouverte par les deux à la ruée des eaux, une traversée d'obstacles naturels, ou la route qu'inventent les oiseaux dans l'espace, somme toute un chemin dans une région interdite au passage normal, un moyen de parcourir une étendue périlleuse ou accidentée" (Benveniste 1954: 297-298).

\section{Amaia}

(11) “(...) il devient impératif de s'assurer que les emplois permettent non seulement de rapprocher des sens qui paraissent différents, mais de motiver leur différence. Dans une reconstruction d'un procés sémantique doivent aussi entrer les facteurs qui provoquent la naissance d'une nouvelle "espèce " du sens. Faute de quoi la perspective est faussée par des appréciations imaginaires” (Benveniste 1954: 295).

Bi-ren hasierako (hots, bi '2' baino lehenagoko) esanahia — bi '*goitik (igaroa)', '*gora (i.)', '*gainetik (i.)' - ${ }^{50}$ eta formaren arrazoiak aurreko lan batean (Lakarra 2010) bilatu ondoren, oraingo honetan bi eta bere ondokoen familia aztertu da: ibi, zubi, hibai, azpi, sabai, aldai, zumai, iztai, zelai, erbi, orbi, garbi, arbi (?) batetik; biguin, begi, beso, bihar, bihi, bihotz, bihur, bizkai, bizkar, bizar, edo bizi (eta are izar, izotz eta isats, izter, eta izpi [ikus "Hitzatzea" Izpazter-ez] bestetik, bide ('igaro-tze') eta bere eratorriak (bidaso, bider) gehi bide ${ }_{2}$ partikula

48. Izur ere *(b)iz-(b)ur-era eraman liteke aurrekoaren antzera, noski, baina ez dakit nola justifika litekeen *(b)iz-ekin lotzea burukoetarik abiatu ezean, bederen, eta *(b)ur-ena ez da garbiago. Ez dirudi, ordea, proposamen hoberik egin denik.

Aldiz, gutxi, baina badirudi badela gizurde/-i-ren lekukorik Lapurdi aldean eta hortaz, izurdi-ren Mitxelenaren etimologiari ( ${ }^{*}$ giza-urde, 1961/1977: 116) eutsi ahal zaiola.

49. Aurrekoetan ere (bizkar, izter, Izpazter...) marka bera genuke. Ez dut hemen toki ez astirik -z-ren balio zaharraz aritzeko (bada oharren bat Lakarra 2013b-n); nolanahi ere, badirudi bakoitzean hedatuago dela gramatikalizazioaren ikertzaileen artean instrumentala soziatibotik ateratzea; bestalde, soziatiboa bera (eta horri lotu plurala) kopulatik eratortzea oso zabaldua da eta euskaraz ere egoki gertatuko litzateke: cf. i-zan : -za [soz./pl.]. Cf. Lakarra 2010n eman zazpi $<$ *bor-za-z-bi, '5 eta 2' soziatiboaren bitartezko koordinazio-egitura, beste hainbat hizkuntzatan legez zenbaki horri eta ingurukoei dagokienez.

50. Parentesiko 'igaro' bi-de-ren bigarren zatiak gauzatzen du, hor baitugu Trasken legearen arabera aditz-izenaren forma sparita (ikus §6). 
barne. Lakarra 2010ko '2'-ren etimologia ( $\left.b i<{ }^{*}-g_{0}(n) i\right)$ sendotu eta aberastu da, markatuaz hainbat $b(i)$-k (eta (b)iz-ek) eta baita -(b)i zenbaitek ere ez duela '2' esanahia, beste zaharrago hura baizik, jatorrian ez ezik oraintsu arte (zenbaitek egungo egunean ere).

Honetarako, Benvenisteri jarraiki (1954: 290), *bi-ren esanahi eta funtzio zaharra haren testuinguru guztiak (gehientsuenak bai, bederen) lotuaz eta bilduaz berreraikitzen saiatu gara. Izan ere, berebiziko laguntza eman digu Benvenisteren lanak, hark *bi eta bide-ren IEzko kidearentzat eriden 'igaro-bide' (franchissement) esanahia gurean ere baliagarri gertatzen baita, bizpahiru dozena hitz argitzeak edo argitzeko bidean jartzeak erakusten digunez. Etimologialariaren lana, berreraikitzailearena legez, ez da inoiz amaitzen, ordea, eta konpli da lan honen hasierako Whitneyren gogoeta buruan izatea (are gehiago Vennemannengandik hartua izaki!).

Benvenisteren laguntza ez da hitz horietara mugatzen, de Lamberteriek laburtzen duen ikerketa programa bikaina eskaintzen baitigu:

(12) “(...) aborder la question du signifié dans le travail de reconstruction, c'est tenter de restituer non pas des formes (ce pour quoi le comparatiste dispose de règles éprouvées, il suffit de les appliquer avec rigueur), ni des realia (ce qui relève du travail du philologue et de l'historien), mais des concepts, c'est-à-dire des opérations mentales. Reconstituer la réalité immatérielle qu'est un procédé de désignation est une tâche d'autant plus délicate que les conditions historiques ou et culturelles dans lesquelles un lèxeme donné a changé de sens ou a pris une acception particulière nous échappent. Or la prise en compte de ces facteurs est essentielle: c'est l'étape obligée pour acceder à une étymologie aceptable du point de vue scientifique, c'est-à-dire une histoire des mots et non seulement l'établissement d'une origine. C'est ici que l'extrapolation de l'histoire à la préhistoire se révèle être une tâche difficile, bien souvent hasardeuse, mais néanmoins nécessaire: la véritable étymologie est à ce prix" (de Lamberterie 2000: 120).

Komeni da, ordea, hierarkiak ez nahastea:

(13) "Si la reconstruction sémantique ne se confond pas avec la reconstruction formelle, elle en est évidemment tributaire, et tout progres dans ce dernier domaine rejaillit sur l'analyse sémantique, car on peut mettre ainsi les données en place d'une manière plus satisfaisante" (de Lamberterie 2000: 114).

\section{Hitzatze}

Ondorengoak etorkizunerako beharko du, aurrekoarekin bistako loturak izan arren ez bainaiz hortik ateratzen diren hari eta adarrak garatzeko egokieran.

Ezagun denez, Izpazter Mitxelenak haitz-en konposizio forma izan zitekeela proposatu 
zuen (FHV 116, 13. oh.), batez ere Azkue eta besteren iz- 'itsaso'-ri aurre egiteagatik. ${ }^{51}$ Goian ikusitakoaren arabera, hobe deritzot *(b)iz-bazter-i, ordea. Izan ere, Mitxelenaren bidetik ezin azal liteke Axpe erruz baina **Axpazter bakar bat ez izatea, eta Izpuru (Aizpuru) gutxi. Gure proposamena, arazo formalok gainditzeaz landa, toponimoaren semantikari egokiago datorkio, Ispaster gain batean baita. Wikipediak zera dio: "La ubicación geográfica de Ispáster no hace descabellado un significado etimológico del tipo "rincón junto al mar" o "rincón junto al agua". Ispáster es una localidad costera, pero la costa es acantilada y de difícil acceso, por lo que localidad ha vivido tradicionalmente de espaldas al mar". Etzana neurea da eta bertatik bertara gauzak ikustean ezin kontrakorik esan; gehienez ere, itsasorantz diren haitzei ere gibel egiten zaiela.

Dosierra osatzen joateko, bada "Izpegi (A.) nom d'une haute montagne entre Baigorry et Baztan d'oú l'on aperçoit la mer" (Lhande), — h- gabe hau ere— eta, nola ez, Donemiliagako (1051) Izpea 'subtus penna' (TAV 44). Honi buruz ere gogoratzekoa iruditzen zait /h/ etimologikoak oraindik beste hiruzpalau mendetan edo ahoskatu zirela lurralde horietan; honenbestez, dakidanez Mitxelenak ez bestek paralelorik aurkeztu ez arren (izan ere ba ote?), $\mathrm{hV}_{1} \mathrm{~V}_{2} \mathrm{C}->\mathrm{V}_{2} \mathrm{C}-$

Baliteke Mitxelenaren haitz- eta nire *(b)iz-en artekoa ez izatea "A ala B"-ko aukera kontu hutsa: horretarako (nirearekikoak oraingoz atzenduaz) Mitxelenak haitz-entzat emandako etimologia (*anetz/*anitz) ukiezintzat izan beharko genuke. Susmatzekoa bide denez, ez da nire ustea aspalditik, hogei urte edo. Kontua da uste hutsekin inora ez goazela eta Mitxelenarenari alternatibarik aurkeztekotan harenaren abantailekin parra egin beharra dela, funtsean $h$ - hori eta dialekto gordetzaileetako bokal sudurkariak azalduaz.

Hori lortuz gero —eta nago bide horretan urratsen bat eman dugula lan honetan $b$-dun eta gabeko (b)ar eta (b)i erro eta morfemen eskutik-, bai, Mitxelenaren forma kanonikoarekiko ezaxola, diptongoen modernotasun erlatiboa, erro zaharren CVC egitura eta gainerakoak atera ahalko genituzke orduan. Horrezaz gainera, haitz-etik guztiz "urruti" ez den hanitz/anhitz-i buruz ere, orain arte baino sendoagorik (handi-rekin zerbait badukeela...) esatea komeniko litzateke. Baina hurrengoan beharko.

\section{Ezgaraiko Gehiketa}

Bi urte baino gehiago bada argitaratzaileei lan honen lehen idaztaldia eman nienetik (berandu orduan ere) eta norbere lanak amaitutzat emateko zenbaitek dugun ohiko ezintasun arruntaz landakorik izan da geroztik, hemen eranskin bidez honako hau eguneratzeko beharra sortzerainokorik.

Lehen ere Vennemannen bitartezko aipu horrek aitortzen zuenez, Xarlesi eskaini nahi niona aski "esperimentala" zen, bide berri arriskutsuak gurutzatzeko eta burutzeko (harako testuko "franchissement" eta pantah haiei lotuaz) Benveniste eta beste zenbait lagun on — gehi

51. Ez dirudi iz- / is- sasiaurrizkiaz aritu ez arduratu beharrik denik Mitxelenak horretaz idatziaren ondoren, nahiz horretaz ohartu ez denik baden: "iz est sûrement un hydronime archaïque..." (Orpustan 2000: 172). 
ausardia poxi bat - aldean harturik abiatu banintzen ere.

Ohiko "aldakortasuna" edo "alda-zaletasuna" labur gelditu da, bidean gertakari larriak izan baitira, nahiz ustez, jazoerak ez gaiztoak izan: aspaldi ohartuak ginen EHHEn gure "ikerketa unitateak" ez zirela hitz solteak, familiak baizik eta horrela geniharduen ere buruak, eratorriak, azpisarrerak eta gainerakoak antolatzen ari.

Haatik, beste familia batzuekin ere (gar-ekin, esaterako) eskarmentu ederrik hartu arren, zur-en familiaren berreraiketak aurrekoek ez bezala markatu gintuen: luze jo zuen —ohi baino askoz luzeago- eta, batez ere artean bestek erakutsi gabeko barneko konplexutasuna aurkitu genuen bertan: hainbat adiera ezberdin nahiz erabateko etenik gabeak eta, batez ere, formazko zertzelada jakingarriak: zun (zaharrena), zur, zul, zuh, zu, zut bokal batekin eta zin, $z i r, z i l$, zih eta zi alomorfoak bestearekin (behintzat) bazituen guztien antolamendu eta loturak argitzea ikaragarri zailduaz:

Baina familia honetako emaitzak onuragarriak dira handik landa EHHEko beste batzuetako lana errazteko eta analisiaren sakontasuna areagotzeko.

Hots, ZUN oinarri duen familiak goian aipatu sare osoa badu, ez ote dute horren parekoa edo horren zati bat bederen su(r), (h)ur, lur eta *bur-ek (azkenarentzat cf. *bun, muño, (g)un(e) eta enparatuak)? U/i txandakatzerik itxaroten ez dugun sar/sal eta gar/gal (nahiz har/al) ezagunetara eta artean alde honetatik miatu gabeko gor ( $\rightarrow$ gol : golde) eta beste zenbaitera BAN / BAR, *BON / BOR-era ere txangoren bat egin beharra izan dugu martxan diren zenbait saiotan, denetan ere emaitza (kognado sare) oparoekin, guk uste.

Egungo egunean aurreko lanetako *gon-i $>$ bi baztergarri ez eze barregarri ere begitantzen zaigu baina aurrerago ere joan gaitezke aipatu lanotako behin-behineko ondorioen bitartez: esan genezake orain ZUN-eko $\mathrm{C}_{2}$-ko txandakatzeak ez direla bakarrak edo halabeharrekoak: lehen ere oihan/oihar-, egun/egur-legu-, soin/sor-, jaun/jaur-, oin/or- eta besteren bat ezagutzen genuen -bitxikeria solte legez, dakidanez ez baitu inor txandakatze horren gibelean diren familien ikerketara eraman - baina orain ezkerreko CVCko $\mathrm{C}_{2}$-ren azterketa zenbaitek askoz eratorri eta konposatu gehiago eta zaharragoak, (zenbait dozena BAN eta *BON-en kasuan) ekarri dizkigu itxaron zitekeen bezala.

Sare tupitu hauek beste fenomeno fonologiko eta morfologiko batzuk ikertzeko ere laguntza berebizikoa ematen digute: har ditzagun $* b$ - $>\emptyset$ - eta $* b$ - $>m$ - aldaketa fonotaktikoak batetik eta hainbat morfema zaharren (DA, DE, DI, DO...) gramatikalizazioa bestetik. Honenbestez horien kronologia erlatiboak eta baita zenbait aldaketa semantikorenak lotzeko bideak urratu dira.

Gure bi, dagoeneko irakurleak pentsa zezakeenez, orain ez bide dugu hitz edo morfema solte bat, *BUN familia erraldoiaren parte txikitxo bat baizik: kide ditu, alegia, bur, bir, bul, bil, bin eta beste $m-z$ hasi zenbait tarteko.

*BUN / BI(C) horretara bilduko bide dira noizbait dozenaka hitz 'buru', 'akabu', 'goiko parte', 'gain'... eta antzeko adieretakoak tartean gure omenduarentzat bildu ditugun bizpahiru dozenak, osorik edo hein batean, bederen; hala itxaroten eta nahi guk behintzat. 


\section{Bibliografia}

Agud, Manuel \& Tovar, Antonio. 1988-95. Materiales para un diccionario etimológico de la lengua vasca (A-orloi). Donostia: ASJU-ren Gehigarriak, 7 lib.

Aikhenvald, Alexandra Y. 2004. Evidentiality. New York: Oxford U.P.

Aikhenvald, Alexandra Y. 2006. "Serial verb constructions in typological perspective", in Alexandra Y. Aikhenvald \& Robert M. W. Dixon (arg.), 1-68.

Aikhenvald, Alexandra Y. \& Robert M. W. Dixon (arg.). 2006. Serial verb constructions. A crosslinguistic typology, Oxford, etab.: Oxford U.P.

Arbelaiz, Juan Jose. 1978. Las etimologías vascas en la obra de Luis Michelena. Tolosa: Kardaberatz.

Benveniste, Émile. 1954. "Problèmes sémantiques de la reconstruction". Berrarg. in Émile Benveniste, Problèmes de linguistique générale. Paris: Gallimard, 289-307.

Corbett, G. C. 2000. Number, Cambridge, etab.: Cambridge U.P.

Corominas, Joan \& José Antonio Pascual. 1980-91. Diccionario crítico etimológico castellano e hispánico. Madril: Gredos, 6 lib.

Epps, Patience. 2006. Growing a numeral system. The historical development of numerals in an Amazonian language family. Diachronica 23. 259-288.

Gómez, Ricardo, Joaquín Gorrochategui, Joseba A. Lakarra \& Céline Mounole (arg.). 2013. Koldo Mitxelena Katedraren III. Biltzarra. UPV/EHU, Vitoria-Gasteiz.

Gorrochategui, Joaquín. 1987. Vasco-céltica. ASJU 21. 951-959.

Heine, Bernd \& Tania Kuteva. 2002. The lexicon of grammaticalization. Oxford U.P.

Lakarra, Joseba A. 1995. "Reconstructing the root in Pre-Proto-Basque", in José I. Hualde, Joseba A. Lakarra \& Robert L. Trask, (arg.), Towards a history of the Basque language, John Benjamins, Amsterdam-Philadelphia: 189- 206.

Lakarra, Joseba A. 2002. "Etymologiae (proto)uasconicae LXV", in Xabier Artiagoitia, Patxi Goenaga \& Joseba A. Lakarra, (arg.), Erramu Boneta. Festschrift for Rudolf P. G. de Rijk. ASJU-ren Gehigarriak 44, Donostia, 425-442.

Lakarra, Joseba A. 2008. Forma canónica, etimología y reconstrucción en el campo vasco. ASJU 37. 261-391.

Lakarra, Joseba A. 2009a. Adabakiak /h/-aren balio etimologikoaz. ASJU 43. 565-596.

Lakarra, Joseba A. 2009b. Forma canónica y cambios en la forma canónica en la prehistoria de la lengua vasca: hacia los orígenes del bisilabismo. Palaeohispanica 10. 557-609.

Lakarra, Joseba A. 2009-2013. ${ }^{*} h_{3}>h_{1},{ }^{*} h_{2}>h_{1}$ eta horiei datxezkien zenbait fenomenoz. Lapurdum 13. 247-272.

Lakarra, Joseba A. 2010. Haches, diptongos y otros detalles de alguna importancia: notas sobre numerales (proto)vascos y comparación vasco-ibérica. Veleia 27. 191-238.

Lakarra, Joseba A. 2011a. Erro monosilabikoaren teoria eta aitzineuskararen berreraiketa: zenbait alderdi eta ondorio. FLV 113. 5-114.

Lakarra, Joseba A. 2011b. "Aitzineuskara: egindakoak eta eginkizunak". In Andoni Sagarna, Joseba A. Lakarra \& Patxi Salaberri (arg.), Pirineoetako hizkuntzak: lehena eta oraina (= Euskaltzaindiaren XVI. Biltzarra, Iruña 6-10/X/2008), 617-694. Bilbo: Iker 26, Euskaltzaindia. 
Lakarra, Joseba A. 2013a. Monosyllabic root theory and the reconstruction of Proto-Basque: some aspects and consequences. In Mikel Martinez Areta (arg.), Basque and ProtoBasque, 173-221. Frankfurt: Peter Lang.

Lakarra, Joseba A. 2013b. "Aitzineuskararen berreraiketa sakonagorantz: forma kanonikoa, tipologia holistikoa, kronologia eta gramatikalizazioa”. In Ricardo Gómez, Joaquín Gorrochategui, Joseba A. Lakarra \& Céline Mounole (arg.), 275-324.

Lakarra, Joseba A. 2015. "Hiru hasperen haboro". In Maria Jose Ezeizabarrena \& Ricardo Gómez (arg.), Eridenen du zerzaz kontenta. Sailkideen omenaldia Henrike Knörr irakasleari (1947-2008), 349-378. Bilbo: UPV/EHUren Argitalpen Zerbitzua.

Lakarra, Joseba A. 2016. "CVC > CV: Gramatikalizazioa morfeman, forma kanonikoak eta berreraiketa morfologikoaren bide berriak. In Gotzon Aurrekoetxea, Jesus MAri Makazaga \& Patxi Salaberri (arg.), Txipi Osmaetxea omenduz. Hire bordatxoan 175192. Bilbo. UPV/EHUren Argitalpen Zerbitzua.

Lakarra, Joseba A. prest.-1. "Para la reconstrucción del verbo protovasco: Irregularidades radicales y antiguas extensiones a la izquierda". UPV/EHUko eskuizkribua.

Lakarra, Joseba A. prest.-2. "Deklinabidearen jatorriaz". UPV/EHUko eskuizkribua.

de Lamberterie, Ch. 2000. "Problèmes sémantiques de la reconstruction en indo-européen". In Jacques François (arg.), Théories contemporaines du changement sémantique, 109-134. Peeters: Leuven.

Lord, Carol. 1993. Historical change in serial verb constructions. Amsterdam: John Benjamins.

Manterola, Julen. 2015. Euskararen morfologia historikorako. Artikuluak eta erakusleak. Towards a history of Basque morphology: articles and demonstratives. UPV/EHUko doktorego tesia.

Mitxelena, Koldo. 1950. "De etimología vasca". Berrarg SHLV, 439-444.

Mitxelena, Koldo. 1954. "Problemas teóricos y prácticos de la lingüística vasca". Berrarg. SHLV, 630-644.

Mitxelena, Koldo. 1954-57. "Diccionario crítico etimológico de la lengua castellana [Iruzkina]". Berrarg. SHLV, 467-491.

Mitxelena, Koldo. 1958. "Hispánico antiguo y vasco". Berrarg. SHLV, 99-106.

Mitxelena, Koldo. 1963. Lenguas y protolenguas. Donostia: Berrarg. ASJUren Gehigarriak 20, 1990.

Mitxelena, Koldo. 1964. Sobre el pasado de la lengua vasca.

Mitxelena, Koldo. 1970. "Nombre y verbo en la etimología vasca". Berrarg., Leioa: Palabras y textos, 283-309, Joaquín Gorrochategui (arg.), UPV/EHU.

Mitxelena, Koldo. 1971. "Gramática generativa y lingüística histórica". Berrarg., Madril: Lengua e Historia. Paraninfo, 55-72.

Mitxelena, Koldo. 1973. Apellidos vascos. 3. arg. Donostia: Txertoa.

Mitxelena, Koldo. 1977 [1961]. Fonética histórica vasca, 2. arg. zuzendu eta emendatua. Donostia: ASJUren Gehigarriak 4.

Mitxelena, Koldo. 1987-2005, Orotariko Euskal Hiztegia-Diccionario general vasco [OEH]. Bilbo, Euskaltzaindia, 16 lib.

Mitxelena, Koldo. 1988, Sobre historia de la lengua vasca [SHLV], Joseba A. Lakarra (arg.), ASJUren Gehigarriak 10, Donostia, 2 lib. 
Mitxelena, Koldo. 2011-2012. Luis Michelena. Obras Completas. Joseba A. Lakarra eta Iñigo Ruiz Arzalluz (arg.), Donostia-Bilbo: ASJUren Gehigarriak, 15 lib.

Orpustan, Jean-Baptiste. 1999. La langue basque au Moyen Age (IXe - XV siècles). Baigorri: Izpegi.

,2000, Les noms des maisons médiévales en Labourd, Basse-Navarre et Soule. Baigorri: Izpegi.

Palay, Simin. 1991 [1932-34]. Dictionnaire du béarnais et du gascon modernes. [3. arg.] Paris: CNRS.

Peterson, David. 2013. "Basque in the Becerro. Basque names and language in the Becerro Galicano of San Millan" in Ricardo Gómez et al. (arg.),

Rey, Alain. (zuz.). 2006. Dictionnaire historique de la langue française. Paris: Dictionnaires Le Robert [1. argit. 1992].

Sagart, Laurent. 1999. The roots of Old Chinese. Amsterdam-Philadelphia: John Benjamins.

Salaberri, Patxi. 1999. [Iruzkina] La langue basque au Moyen Age. RIEV 44. 205-209.

Sarasola, Ibon. 2005. Euskal hiztegia. Donostia: Gipuzkoako Kutxa.

Schuh, G. 2013. "Word families in Hausa". In O.-M. Ndimele, M. Ahmad \& H.M. Yakasai (arg.), Language, literature and culture in a multilingual society. A festschrift for Abubakar Rasheed, 579-598. Port Hardcourt: M. \& J. Grand Orbit Communications.

Uhlenbeck, Cornelius C. 1949. Los nombres vascos de miembros de cuerpo que comienzan con b-. Eusko Jakintza 3. 105-111. 1927ko alemanierazko orijinalaren itzulpena ("Die mit b-anlautenden Körperteilnamen des Baskischen", FS. Meinhof 1927, 351-357).

Watkins, Calvert. 1965. "Latin nox 'by night': a problem in syntactic reconstruction" in Selected Writings: I. Language and Linguistics; II. Culture and Poetics, 105-126. Ed. by Lisi Oliver. Innsbruck: Innsbrucker Beiträge zur Schprachwissenschaft 1994, 2 lib.

Watkins, Calvert. 1984. "Lapport d'Emile Benveniste à la grammaire comparée" in Guy Serbat (arg.), Émile Benveniste aujourd'hui. Actes du Colloque international du CNRS, I, 3-11: Louvain: Peeters.

Watkins, Calvert. 1990, "Etymologies, equations, and comparanda: types and values, and criteria for judgement". In Ph. Baldi (arg.), Linguistic change and reconstruction methodology, 289-304. Berlin-New York: Mouton de Gruyter.

Zavala, R., 2006, "Serial verbs in Olutec (Mixean)", in Alexandra Y. Aikhenvald \& Robert M. W. Dixon (arg.), 273-300. 
Eranskina: aztertutako formak (zenbakiak atalenak dira)

$-\operatorname{ago}<$ *ha-go 7 ,

aldai 2 .

*alde-bi 2 ,

*alde-Ci 2 ,

arte $<$ *bar-te 4 ,

-bai 2 ,

barda 1 ,

baso 7 ,

bazter 7 ,

bazter $<$ *uraz- (i?) 7 ,

bazter $<{ }^{*}$ bar-z-be(he)-r(a) 7 ,

begi< $<$ bi-hegi 5 ,

beso 5 ,

*bezu 11 ,

*bezu-bar 11 ,

*bezu-gain > ezpain 11,

$b i<{ }^{*} g w i<{ }^{*} g o(n) i 4$,

-bi passim,

bi- passim,

*bi-z-arro 11,

*bi-z-bar-bi 2,

bi-z-i > bizi 11,

*bi-bun-e > biguin, bigun 10,

*bi-esk(u)-so 5 ,

*bi-sats 10,

*bi-z- 4 ,

bidaso 7 ,

Bidasoa 7 ,

bide 6 ,

bide $<*$ bi-de 6, 7 ,

*bide-so 7 ,

bide $>$ *-bie $>$-bi (i?) 4 ,

bide izan 8 ,

bidegabe 8 ,

bider 7 ,

bider $<$ *bide-ber 7 ,

biderreko 7 ,

biderre $(t)$ an 7 ,

biderrez 7 ,

bidez 8 ,

bidezko 8,

biguin, bigun 10 ,

bihar 9 , bihar < *bi-har 9 ,

bihi 10,

bihi < *bi-ihi 10,

bihotz 9 ,

bihotz< $<$ bi-hotz 9 ,

bihur 9 ,

bihur $<*$ *bi-hor 9 ,

bizar 11 ,

bizar < *bi-zar (i?) 11,

bizka(h)i 2,

*bun 10

*egu-da 1 ,

erbi 4 ,

etzan/-in/-un < *atze-edon

finu $>$ bigun (i?) 10 ,

* gar 2,

* gar-bar-bi > garai 2 ,

* gar-bi > garbi 2, 4,

garai 2 ,

* gara-i $>$ garai (i?) 2 ,

garbi 2, 4,

*gaur-da 1 ,

gizurde, -di 11,

(g)une $<*$ (b) un (e) 10 ,

harbi < *har (i)-bi 4 ,

Haritx-zelhar 2,

*hatz-bi > azpi 5 ,

*heri/erhi-bi > erbi 4 ,

herpin 4 ,

herpin $<*$ erhi-bin 4 ,

*hertz-bu(n)-ger > esker 11,

*hertz-bu(n)-hon(e) > eskui 11 ,

*hertz-hari > estari 11,

hibai < *hur-ban-i (i?) 3,

hibai<*hur-bar-bi 3 ,

hozi 9 ,

*hur-ban-i (i?) 2 ,

*hur-bar-bi 2 ,

i- $<$ *bi-

i-ra-go 7 ,

*ibahi 3 ,

Ibahi 3 ,

*ibi-erdi 1 , 
ilhun < *hil-(b)un 10,

ipurdi 1 ,

isats 10 ,

itzali < *atze-jali 10,

itzaungi $<$ *atze-edadongi 10 ,,

itzuli <*atze-eduli 10,

izar 11 ,

izotz< *hur-zotz 10,

izotz<*bi-zotz 10,

Izpazter (Ispaster) $<*$ (b)iz-bazter

11

izpi 11,

izpi $<*(b) i z-b i 11$,

iztai < *izter-bi 2 ,

iztegi 11 ,

izter 7,11 ,

izter $<*(b) i z-b e(h e) r(a) 11$,

izorra 11 ,

izur 11 ,

izurde 11,

laso 7 ,

laster < *lats-be(he)r(a) 7, 11,

luban/-baki 2,

*lur-ban 2,

muno, -ño $<$ *bun-no/-ño 10 ,

*oin-bi > orbi 4 ,

orbi 4,

sabai 2 ,

-so 5,7 ,

uda 1 ,

xixter 11,

*zel-bar-bi > zelai 2 ,

zelai 2 ,

zelar 2 ,

zortzi $<$ zorrotzi 4 ,

zubi 2 ,

zumai 2 ,

*zur-bar-bi 2 ,

*zur-bi > zubi 4,

*zur-hor > zuhur 10, 